\title{
Glial Cells Decipher Synaptic Competition at the Mammalian Neuromuscular Junction
}

\author{
Houssam Darabid, ${ }^{1,2}$ Danielle Arbour, ${ }^{1,2}$ and Richard Robitaille ${ }^{1,2}$ \\ ${ }^{1}$ Département de physiologie, Université de Montréal, Montréal, Quebec, H3C 3J7 Canada, and ²Groupe de recherche sur le système nerveux central, \\ Université de Montréal, Montréal, Quebec H3C 3J7, Canada
}

It is now accepted that glial cells actively interact with neurons and modulate their activity in many regions of the nervous system. Importantly, modulation of synaptic activity by glial cells depends on the proper detection and decoding of synaptic activity. However, it remains unknown whether glial cells are capable of decoding synaptic activity and properties during early postdevelopmental stages, in particular when different presynaptic nerve terminals compete for the control of the same synaptic site. This may be particularly relevant because a major determinant of the outcome of synaptic competition process is the relative synaptic strength of competing terminals whereby stronger terminals are more likely to occupy postsynaptic territory and become stabilized while weaker terminals are often eliminated. Hence, because of their ability to decode synaptic activity, glial cells should be able to integrate neuronal information of competing terminals. Using simultaneous glial $\mathrm{Ca}^{2+}$ imaging and synaptic recordings of dually innervated mouse neuromuscular junctions, we report that single glial cells decipher the strength of competing nerve terminals. Activity of single glial cells, revealed by $\mathrm{Ca}^{2+}$ responses, reflects the synaptic strength of each competing nerve terminal and the state of synaptic competition. This deciphering is mediated by functionally segregated purinergic receptors and intrinsic properties of glial cells. Our results indicate that glial cells decode ongoing synaptic competition and, hence, are poised to influence its outcome.

\section{Introduction}

Glial cells were long considered as a support element for neurons providing essential energy metabolites and maintaining the ionic balance of the extracellular environment. However, there is now a large body of evidence revealing that glial cells actively interact with neurons and are important for proper information processing in the nervous system. Indeed, glial cells detect synaptic activity at the synapse and, in turn, release neuroactive molecules that modulate neurotransmission (Robitaille, 1998; Fellin et al., 2004; Panatier et al., 2006; Henneberger et al., 2010; Todd et al., 2010; Panatier et al., 2011).

Involvement of glial cells in the regulation of synaptic activity and plasticity heavily depends on their ability to detect and decode synaptic activity (Auld and Robitaille, 2003; Todd et al., 2010; Panatier et al., 2011). However, these neuron-glia interactions were addressed solely in the mature nervous system,

Received June 15, 2012; revised Nov. 1, 2012; accepted Nov. 29, 2012.

Author contributions: H.D., D.A., and R.R. designed research; H.D. and D.A. performed research; H.D. and D.A. analyzed data; H.D., D.A., and R.R. wrote the paper.

This work was supported by the Canadian Institutes for Health Research Operating Grant MOP-14137 to R.R., the Canadian Foundation of Innovation (equipment grant) and Fonds Recherches Quebec-Santé (FRQ-S, infrastructure grant) to the Groupe de recherche sur le Système Nerveux Central. R.R. was a Chercheur-National of FRQ-S. H.D. held an FRQ-S studentship. D.A. held a studentship from the National Science Engineering Research Council of Canada. We thank Dr Aude Panatier for reading the manuscript and for generous and insightful discussion over the course of this work, Dr Jaideep Bains and Dr Keith Murai for reading the manuscript, and Dr Arlette Kolta for the use of her confocal system.

The authors declare no competing financial interests.

Correspondence should be addressed to Dr. Richard Robitaille, Département de physiologie, Université de Montréal, Montréal, Quebec, H3C 3J7 Canada. E-mail: richard.robitaille@umontreal.ca.

DOI:10.1523/JNEUROSCI.2935-12.2013

Copyright $\odot 2013$ the authors $\quad 0270-6474 / 13 / 331297-17 \$ 15.00 / 0$ whereas their activity at immature synapses remains ill-defined despite their essential role in synapse formation and elimination (Ullian et al., 2004; Christopherson et al., 2005; Eroglu and Barres, 2010). An event where the ability of glial cells to detect synaptic activity could come to play is the postnatal synaptic competition that occurs between supernumerary nerve terminals competing for the same synaptic territory (Lohof et al., 1996; Chen and Regehr, 2000; Wyatt and Balice-Gordon, 2003). This competition results in the strengthening of certain synaptic inputs and weakening and elimination of others (Colman et al., 1997; Kopp et al., 2000; Keller-Peck et al., 2001; Walsh and Lichtman, 2003; Bishop et al., 2004). Synaptic competition and elimination are in part dependent on the relative activity of the competing nerve terminals (Balice-Gordon and Lichtman, 1994; Stellwagen and Shatz, 2002; Buffelli et al., 2003) where the most active inputs (i.e., releasing more neurotransmitters) are more likely to be strengthened and maintained (Busetto et al., 2000; Buffelli et al., 2003). Hence, glial cells could alter the outcome of synaptic competition because of their ability to detect and modulate transmitter release. However, a fundamental prerequisite remains undetermined: glial cells must be able to detect ongoing synaptic competition and decipher the strength of each competing nerve terminal. To address this question, we used the mammalian neuromuscular junction (NMJ), a well-characterized model for the study of synaptic competition (Kopp et al., 2000; Walsh and Lichtman, 2003; Chung and Barres, 2009) and neuron-glia interactions (Robitaille, 1998; Todd et al., 2010).

Using simultaneous $\mathrm{Ca}^{2+}$ imaging of perisynaptic Schwann cells (PSCs), glial cells at the NMJ, and synaptic recordings of dually innervated NMJs, we show that a single PSC deciphers 
ongoing synaptic competition. Based on their intrinsic properties and segregated functional $\mathrm{P} 2$ Y receptors, $\mathrm{PSC}$ decode the properties of each competing input, identifying the strong from the weak input. Hence, PSCs are in tune with the synaptic competition process, selectively decoding the state of each competing nerve terminals.

\section{Materials and Methods}

Animals and nerve-muscle preparation. All experiments were performed in accordance with the guidelines of the Canadian Council of Animal Care and the Comité de déontologie animale of Université de Montréal.

P7-P8 male CD-1 mice (Charles River) were anesthetized by a lethal intraperitoneal injection of a ketamine $(15 \mathrm{mg} / \mathrm{ml})$ and xylazine $(1 \mathrm{mg} /$ $\mathrm{ml})$ mixture. The soleus muscle (SOL) and its innervation to the ventral roots were dissected according to Kopp et al. (2000) under oxygenated $\left(95 \% \mathrm{O}_{2}, 5 \% \mathrm{CO}_{2}\right.$ ) Rees' Ringer's solution (in $\mathrm{mm}$ ): $110 \mathrm{NaCl}, 5 \mathrm{KCl}, 1$ $\mathrm{MgCl}_{2}, 25 \mathrm{NaHCO}_{3}, 2 \mathrm{CaCl}_{2}, 11$ glucose, 0.3 glutamate, 0.4 glutamine, 5 BES, $4.34 \times 10^{-7}$ cocarboxylase and 0.036 choline chloride. The $\mathrm{pH}$ of oxygenated solution was at 7.3. The SOL and its innervation were pinned in a Sylgard-coated recording chamber, and the ventral roots were carefully divided in three segments that were independently stimulated by three suction-stimulating electrodes (square pulses; $0.1 \mathrm{mV}$ to $2.0 \mathrm{~V}, 0.1$ ms duration) using a Master- 8 stimulator (AMPI). This preparation allowed us to stimulate two distinct inputs competing at single NMJ, as described in Figure $1 A$.

Immunohistochemistry of NMJ components. Immunohistochemical labeling was performed according to Todd et al. (2010). In brief, dissected SOL muscles were pinned in a Sylgard-coated dish and fixed for $10 \mathrm{~min}$ in $4 \%$ formaldehyde at room temperature and then permeabilized in $100 \%$ cold methanol for $6 \mathrm{~min}$ at $-20^{\circ} \mathrm{C}$. Nonspecific labeling was minimized by incubating the muscles in a solution of $10 \%$ normal donkey serum (NDS) and $0.01 \%$ Triton X-100 for $20 \mathrm{~min}$. Nerve-muscle preparations were incubated overnight at $4^{\circ} \mathrm{C}$ with a rabbit anti-S100 $\beta$ (1:250, Dako, with $0.01 \%$ Triton X-100 and $2 \%$ NDS). After rinsing, muscles were incubated in a goat anti-neurofilament (1:250; SC16143, Santa Cruz Biotechnology) and chicken anti-synaptotagmin (1:250; AB9356, Millipore Bioscience Research Reagents) for $90 \mathrm{~min}$. Secondary antibodies (Alexa $488 \alpha$-goat, FITC $\alpha$-chicken and $647 \alpha$-rabbit, 1:500) were incubated together for $60 \mathrm{~min}$ at room temperature. Muscles were incubated with $\alpha$-bungarotoxin (Alexa 594, $0.75 \mu \mathrm{g} / \mathrm{ml}$ ) for $45 \mathrm{~min}$. After each step, muscles were rinsed in PBS containing $0.01 \%$ Triton X-100 for 5 min. The preparations were then mounted in the Prolong Gold antifade reagent containing DAPI (Invitrogen) to visualize nuclear material. All labels were observed simultaneously using the spectral detection feature of an Olympus FV1000 confocal microscope. Pinholes were set to obtain an airy disk value of 1 . No further manipulations of the images were performed after the acquisition.

The identification and count of PSCs at NMJs were performed on muscles that were either used for electrophysiological recordings or freshly dissected and processed directly for immunostaining. When the same muscles were used for electrophysiological recordings and immunostaining, the recorded NMJs were identified post hoc using their specific location on the muscle using the distance of the fiber from the nerve entry as reference and the pattern of nerve branching since only one NMJ was present on each muscle fiber. The following parameters were used to identify and count PSCs at NMJs: cells needed to be S100 $\beta$ immunopositive, labeled by DAPI and located within the endplate area. PSCs somata were well separated and easily identified even though their processes are known to intermingle around the nerve terminals.

Immunohistochemistry of $P 2_{Y} 1$ receptors. We could not label PSCs using the rabbit anti-S100 $\beta$ as indicated above because type $1 \mathrm{P} 2$ Y receptors $\left(\mathrm{P} 2_{\mathrm{Y}} 1 \mathrm{R}\right)$ were labeled using a polyclonal antibody also generated in rabbit. Instead, PSCs were selectively loaded using a single cell electroporation method. Dissected SOL muscles were pinned in a Sylgard-coated recording chamber and constantly perfused with oxygenated Rees' Ringer's solution. A glass pipette (5-8 M $\Omega$ ) was filled with $5 \mathrm{mg} / \mathrm{ml}$ fixable anionic Dextran, AlexaFluor-594 (10,000 MW; Invitrogen). The pipette was mounted on a pipette holder with a platinum stimulating wire con- nected to a Master-8 stimulator (AMPI), and the reference electrode was placed in the bath. The pipette was positioned close to the soma of a PSC using a micromanipulator under visual guidance. One to 3 single square pulses (10 ms duration; $10 \mathrm{~V}$ amplitude) were applied to open the cell membrane (Nevian and Helmchen, 2007) and allow the loading of AlexaFluor-594 into the cell. The procedure was repeated to load other visible PSCs at the same NMJ. PSCs from 3 to 4 NMJs were loaded per muscle. Muscles were allowed to rest for $30 \mathrm{~min}$ before fixation and immunohistochemistry staining. Loaded PSCs/NMJs were identified post hoc using the specific shape of the PSCs and the fiber distance from the nerve entry as a reference as indicated above. Three muscles were used as control to confirm that electroporated PSCs were also immunopositive for $\mathrm{S} 100 \beta$ (data not shown).

Muscles were then incubated overnight with a rabbit antibody against $\mathrm{P} 2_{\mathrm{Y}} 1$ receptors $(1: 1500 ; 34-7200$, Invitrogen). After rinsing, muscles were incubated in a goat antineurofilament (1:250; SC16143, Santa Cruz Biotechnology) and mouse antisynaptic vesicular protein SV2 IgG1 (1:1500; Developmental Studies Hybridoma Bank) for $120 \mathrm{~min}$ at room temperature. Preparations were incubated with Alexa Fluor $488 \alpha$-goat and Alexa Fluor $647 \alpha$-rabbit (1:500) secondary antibodies for $60 \mathrm{~min}$ and then incubated with DL488 $\alpha$-mouse IgG1 (1:500) for $60 \mathrm{~min}$ at room temperature. Finally, muscles were incubated with $\alpha$-bungarotoxin (Alexa Fluor 594, $0.75 \mu \mathrm{g} / \mathrm{ml}$ ) for $45 \mathrm{~min}$. After each step, muscles were washed in PBS containing $0.01 \%$ Triton X-100 (3 times, 5 min each). The preparations were then mounted in the Prolong Gold antifade reagent and all labels observed simultaneously using the spectral detection feature of an Olympus FV1000 confocal microscope.

Immunohistochemistry of muscarinic receptors M5 and M3. For labeling muscarinic receptors (mAChRs), muscles were incubated overnight at $4^{\circ} \mathrm{C}$ with a rabbit anti-S100 $\beta$ (1:250, Dako) to label PSCs. After rinsing, muscles were incubated with a chicken antineurofilament to label axons and nerve terminals (1:1000; 212-901-D84, Rockland), mouse anti-SV2 IgG1 to label active zones (1:1500; Developmental Studies Hybridoma Bank), and goat anti-M3 (1:500, SC31486, Santa Cruz Biotechnology) or M5 (1:500, SC7478, Santa Cruz Biotechnology) to label mAChRs, all at room temperature for $120 \mathrm{~min}$. Nerve-muscle preparations were then sequentially incubated in the following secondary antibody solutions for $60 \mathrm{~min}$ at room temperature: Alexa Fluor $488 \alpha$-chicken (1:500, antineurofilament primary antibody) with Alexa Fluor $647 \alpha$-goat (1:500 for M5 or 1:1000 for M3), DL488 $\alpha$-mouse IgG1 (1:500; anti SV2 primary antibody), and finally Alexa Fluor $405 \alpha$-rabbit (1:500). Preparations were rinsed with PBS containing $0.01 \%$ Triton X-100 (3 times, 5 min each) in between each antibody incubation. Finally, muscles were incubated with $\alpha$-bungarotoxin (Alexa Fluor 594, $0.75 \mu \mathrm{g} / \mathrm{ml}$ ) for $45 \mathrm{~min}$ and, after washout, preparations were mounted in the Prolong Gold antifade reagent. All labels were observed simultaneously using an Olympus FV1000 confocal microscope.

Electrophysiological recordings of synaptic transmission. Intracellular recordings of endplate potentials (EPPs) were performed at $28^{\circ} \mathrm{C}-30^{\circ} \mathrm{C}$ using glass microelectrodes (40-70 $\mathrm{M} \Omega$, filled with $\mathrm{KCl}, 3 \mathrm{M}$ ). Only NMJs that showed EPPs evoked by the independent stimulation of two of the three ventral roots were studied. Each suction electrode contained only a single axon that innervated the NMJ because only a single EPP with given amplitude and rise time was induced by the stimulation. Increasing threshold stimulation intensity never evoked any sudden increase in EPP amplitude (EPP steps), as would be expected if multiple axons innervating a single poly-innervated NMJs were present within the stimulated stimulating electrode (Redfern and Thesleff, 1971; Busetto et al., 2000; Buffelli et al., 2002). Synaptic responses were recorded using an Axoclamp 2B amplifier (Axon Instruments) and further amplified (100×) and filtered at $2 \mathrm{kHz}$ by a Warner Instruments DC amplifier. EPPs were recorded with WinWCP software (John Dempster, University of Strathclyde, Strathclyde, United Kingdom).

Synaptic strength of each nerve terminal in competition at a given NMJ was determined by measuring their respective quantal content and paired-pulse facilitation. These were determined using a modified Ringer's solution with low $\mathrm{Ca}^{2+}(1 \mathrm{~mm}) / \mathrm{high} \mathrm{Mg}^{2+}(6-7 \mathrm{~mm})$ solution. The ventral roots were stimulated at a frequency of $0.2 \mathrm{~Hz}$ with an intensity that was twice the threshold for eliciting EPPs. Quantal content $(\mathrm{m})$ for 
A

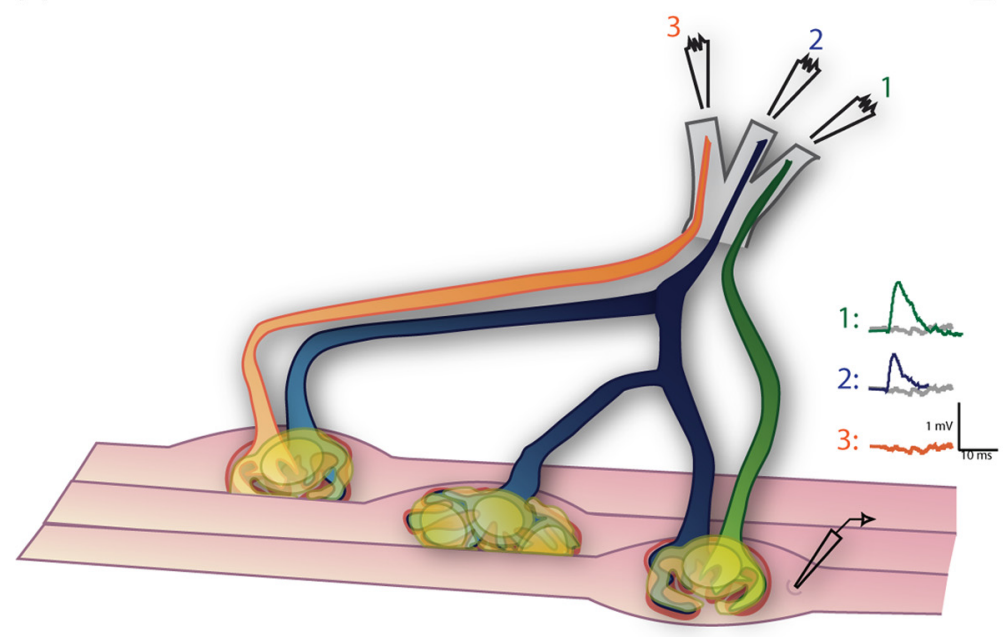

B

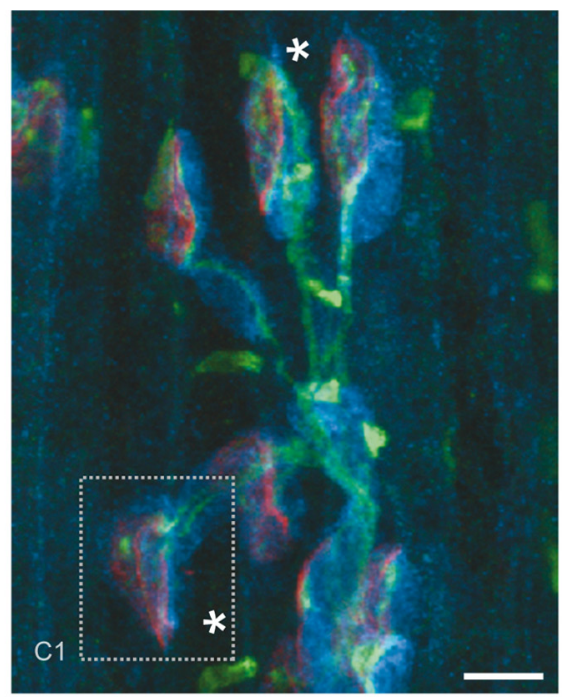

C1

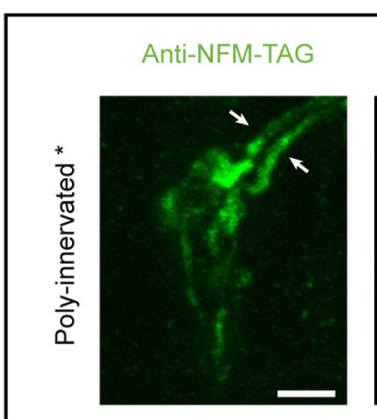

$\alpha$-Bungarotoxin

$S 100 \beta$
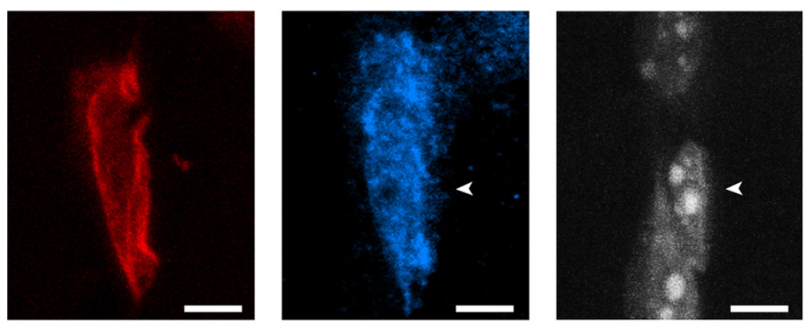

garotoxin

$+S 100 \beta+D A P$

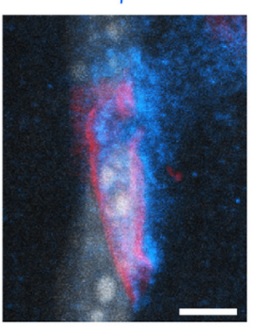

C2
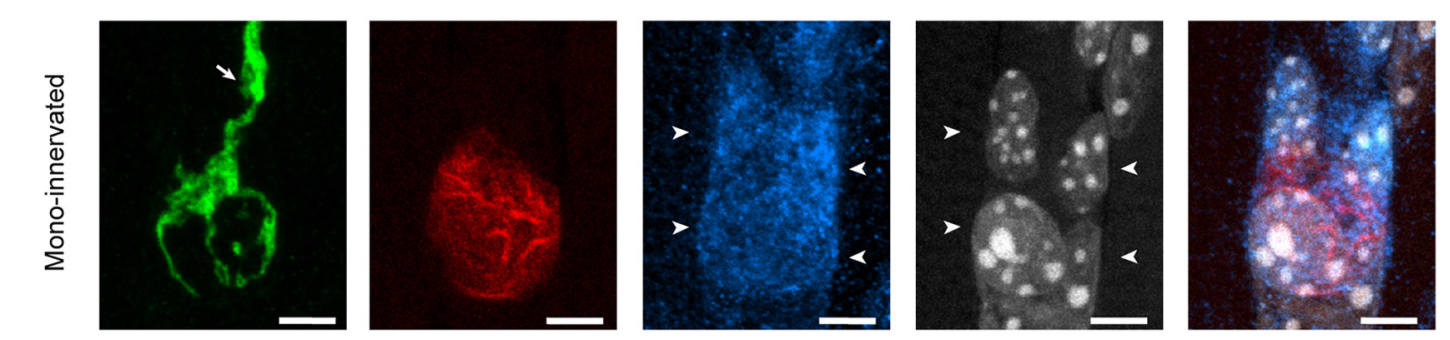

D

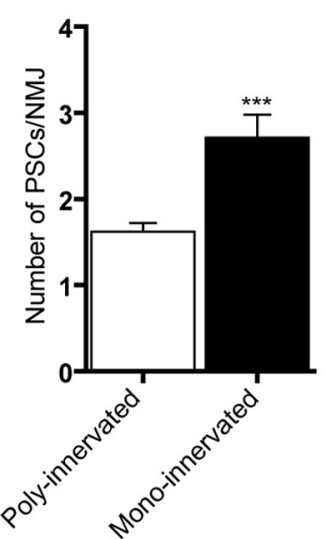

E

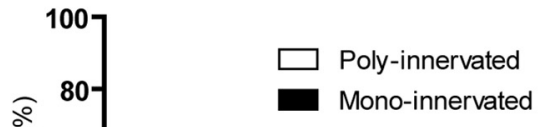

Figure 1. PSCs during synaptic competition at the mammalian NMJ. $A$, Diagram illustrating the experimental situation where transmitter release from a dually innervated NMJ was recorded with a sharp microelectrode and synaptic responses evoked by independent stimulation of two different ventral roots. B, Labeling of presynaptic terminals (green), PSCS (blue), and postsynaptic nAChR (red) of P7 Soleus NMJs. At this age, most NMJs were poly-innervated (as shown in (1 and marked with “*”), but some NMJs were already mono-innervated. C1, At dually innervated NMJs, two independent axonal branches (in green, arrows) converged at the same endplate area (red). Also note that a single PSC (blue) covered the whole endplate area and both nerve terminals. PSCs counted (arrowheads) were positive for S100 $\beta$ (blue) and DAPI (gray) staining and were located at the endplate (red).C2,Atmono-innervated NMJs, one axon (in green, arrow) was observed at the endplate area (red). This NMJ was from another muscle preparation than in $\boldsymbol{B}$ and $\mathbf{C 1}$. D, Histogram of the number of PSCs at poly-innervated and mono-innervated NMJs. Note that there were more PSCs at mono-innervated than poly-innervated NMJs. Unpaired $t$ test, $p<$ 0.0001. E, Distribution of the number of PSCs at mono-innervated and poly-innervated NMJs. Note that most poly-innervated NMJs had 1 or 2 PSCs. Scale bars: B, $10 \mu \mathrm{m} ; \mathbf{C 1}_{1}, \mathbf{C 2}, 5 \mu \mathrm{m}$. 
each input was determined using the method of failures (Del Castillo and Katz, 1954): $\mathrm{m}=\log _{\mathrm{e}}$ (no. of nerve impulses/no. of failures).

To determine the paired-pulse facilitation (F), two stimuli $(0.1 \mathrm{~ms}$ duration) were given with an interval of $10 \mathrm{~ms}$ and facilitation was calculated as the mean amplitude of the second responses (B) divided by the mean amplitude of the first responses (A) (including failures).

$\mathrm{Ca}^{2+}$ imaging of PSCs. PSCs were loaded with the $\mathrm{Ca}^{2+}$ indicator fluo-4AM (10 $\mu \mathrm{M}$, Invitrogen) by incubating nerve-muscle preparations for two times $35 \mathrm{~min}$ at room temperature. The loading solution also contained $0.02 \%$ pluronic acid (Invitrogen) and $0.5 \%$ dimethylsulfoxide (Sigma) added to the preoxygenated normal Ringer solution. This method is known to load preferentially PSCs at NMJs, and cells were easily identifiable in fluorescent illumination for the $\mathrm{Ca}^{2+}$ indicator (fluo-4) and transmitted light (Rochon et al., 2001; Rousse et al., 2010; Todd et al., 2010). $\mathrm{Ca}^{2+}$ responses were elicited in PSCs by independently stimulating each ventral root at $50 \mathrm{~Hz}$ for $30 \mathrm{~s}$. Preparations were allowed to rest for $20 \mathrm{~min}$ between stimulation of the two competing inputs.

Changes in fluorescence intensity were monitored using a Bio-Rad MRC600 laser-scanning confocal microscope equipped with an argon ion laser. The imaging area was focused on a single NMJ, and all PSCs present at that NMJ were imaged at once. The preparation was excited with a $488 \mathrm{~nm}$ laser line and the emitted fluorescence was detected through a long-pass filter at $590 \mathrm{~nm}$. A $60 \times$ water-immersion lens was used (0.90 NA; Olympus). Relative changes in fluorescence intensity were analyzed over PSCs soma and were expressed as $\% \Delta \mathrm{F} / \mathrm{F}=\mathrm{F}-$ $\mathrm{F}_{\text {rest }} / \mathrm{F}_{\text {rest }} \times 100$.

In some experiments, $\mathrm{Ca}^{2+}$ responses in PSCs were elicited by agonists applied locally using a Picospritzer II (Parker Instruments, positive pressure pulses of $10 \mathrm{PSI}, 150 \mathrm{~ms}$ ) from a glass pipette ( $5 \mathrm{M} \Omega, \sim 2-\mu \mathrm{m}$-tip diameter) positioned at proximity of the cells. Agonists, ATP $(3 \mu \mathrm{M}$, Sigma), muscarine ( $5 \mu \mathrm{M}$, Sigma), or acetylcholine ( $5 \mu \mathrm{M}$ ) were diluted in the extracellular Ringer solution used for the experiment.

All $\mathrm{Ca}^{2+}$ imaging experiments were performed in normal $\mathrm{Ca}^{2+}$ / $\mathrm{Mg}^{2+}$ concentration Ringer's solution at $28^{\circ} \mathrm{C}$ to $30^{\circ} \mathrm{C}$. Muscle contractions were prevented by blocking postsynaptic cholinergic receptors with D-tubocurarine chloride (2.8-3.9 $\mu \mathrm{M}$, Sigma) or $20 \mu \mathrm{M} \alpha$-bungarotoxin (Invitrogen). For experiments where synaptic strength was first established in low $\mathrm{Ca}^{2+} /$ high $\mathrm{Mg}^{2+}$ Rees' solution, preparations were perfused with normal $\mathrm{Ca}^{2+} / \mathrm{Mg}^{2+}$ Ringer for 30 min before imaging $\mathrm{Ca}^{2+}$.

Antagonist applications. In some experiments, antagonists of $\mathrm{P} 2 \mathrm{Y}(\mathrm{Re}-$ active Blue 2 [RB2], $20 \mu \mathrm{M}$, Alexis) or muscarinic receptors (atropine, 20-80 $\mu \mathrm{M}$ or scopolamine, $20 \mu \mathrm{M}$, Sigma) were bath applied for $20-45$ min before the start of the experiment. Stock solutions were prepared in the same extracellular Rees' solutions.

TEA application. Neurotransmitter released by either weak or strong nerve terminal was increased using a $\mathrm{K}^{+}$channel blocker, tetraethyl ammonium (TEA, $0.5 \mathrm{~mm}$ ). First, a dually innervated NMJ was identified and synaptic strength of competing terminals determined. The nonpotentiated input was stimulated first at high frequency ( $50 \mathrm{~Hz}$ for $30 \mathrm{~s}$ ), and evoked PSC $\mathrm{Ca}^{2+}$ responses were recorded under normal Ringer solution. Then, TEA was bath applied for $30 \mathrm{~min}$ and synaptic activity was monitored. Then, the second input (now potentiated by TEA) was stimulated at high frequency and the corresponding PSC $\mathrm{Ca}^{2+}$ responses were recorded. In some control experiments, agonists (ATP, $10 \mu \mathrm{M}$ ) were locally applied in the presence of TEA by micropressure as indicated above.

Statistical analysis. Results are presented as mean \pm SEM, and $N$ represents the number of PSCs. Unless otherwise stated, only one PSC/NMJ was kept for further analyses. Paired $t$ tests were performed when comparing responses induced by the two competing terminals during the same experiment. When data were found not to conform to normality, Mann-Whitney $\mathrm{U}$ tests were used. Unpaired $t$ tests were performed to compare two different conditions from different experiments. One-way Kruskal-Wallis ANOVA test with Dunn's Multiple-Comparison posttest were used to compare three groups or more. Analyses were deemed significant at $p<0.05$.

\section{Results}

The NMJ has proven to be one of the most useful models to study synaptic competition and elimination. However, although the presynaptic and postsynaptic changes have been studied, very little is known about PSCs during synaptic competition and elimination at the NMJ.

In this work, we investigated PSC properties and activity at P7-P8 dually innervated NMJs and their ability to decipher ongoing synaptic competition.

\section{PSCs at dually innervated NMJs}

More than $60 \%$ of NMJs are poly-innervated and undergoing synaptic competition at P7-P8 mice (Kopp et al., 2000). Lichtman and colleagues showed that each competing nerve terminal could occupy a segregated territory of endplate area (Gan and Lichtman, 1998; Walsh and Lichtman, 2003; Bishop et al., 2004), whereas Hirata et al. (1997) showed that one or two PSCs are present at poly-innervated rat NMJs.

Here, the state of synaptic innervation was determined using the presence of synaptic responses evoked by independent stimulation of ventral roots (Fig. 1A) and by immunohistological labeling of PSCs and presynaptic and postsynaptic elements (Fig. $1 B)$. The number of PSCs was based on the criteria described in the experimental procedures using S100 $\beta$ labeling of PSCs combined with nuclear staining with DAPI (Fig. 1C1-2). Consistent with Hirata et al. (1997), we found an average of $1.6 \pm 0.1$ (8 muscles, 37 NMJs) PSCs at poly-innervated NMJs and $2.7 \pm 0.2$ at mono-innervated NMJs (Fig. 1D, E; 8 muscles, 14 NMJs; unpaired $t$ test, $p<0.0001$ ). We observed that $43.3 \%$ of polyinnervated NMJs were covered by one PSC, whereas $51.3 \%$ were covered by two PSCs. Only two NMJs had three PSCs (5.4\%). In contrast, mono-innervated NMJs were generally associated with two or more PSCs (14.3\% with one PSC, $21.4 \%$ with two PSCs, $42.9 \%$ with three PSCs, and $21.4 \%$ with four PSCs; Fig. 1E). Importantly, it appears that the number of PSCs is directly related to the state of synaptic competition (i.e., mono-innervated vs poly-innervated) where fewer cells appear to be present during the course of synaptic competition. Furthermore, these results show that both competing nerve terminals at a poly-innervated NMJ were often covered by a single PSC. In this work, only dually innervated NMJs were studied while the number of PSCs present was determined.

\section{A single PSC detects neurotransmitter release from competing nerve terminals at dually innervated NMJs}

A fundamental prerequisite for PSCs to decode ongoing synaptic competition is that they are synaptically responsive, detecting synaptic activity generated by both competing nerve terminals. To test this possibility, we examined the ability of PSCs to respond to synaptic activity of each individual competing nerve terminal evoked by independent ventral root stimulation. Dually innervated NMJs with one or two PSCs were chosen, and each competing nerve terminal was independently stimulated at $50 \mathrm{~Hz}$ for $30 \mathrm{~s}$, a pattern and frequency reported in vivo for tonic firing of motor neurons innervating the SOL at P7-P8 (Gorassini et al., 2000; Eken et al., 2008). PSC activity was assessed by monitoring changes in intracellular $\mathrm{Ca}^{2+}$ levels, known to be a reliable reporter of their level of excitation and responsiveness (Jahromi et al., 1992; Robitaille, 1998; Rochon et al., 2001).

As shown in Figure 2, independent stimulation of each competing nerve terminal induced $\mathrm{Ca}^{2+}$ response at the soma of the same PSC. From all tested NMJs, $85.7 \%$ of PSCs responded to 
A

PSC $\mathrm{Ca}^{2+}$-response induced by Input 1

PSC Ca ${ }^{2+}$-response induced by Input 2

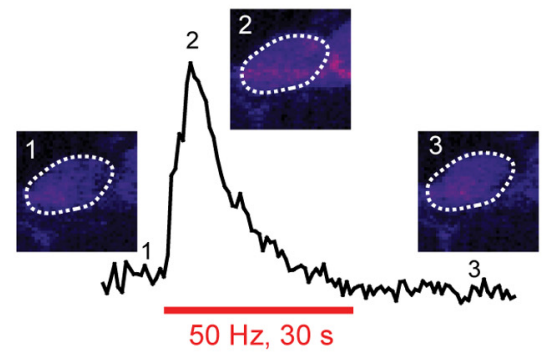

$\mathrm{B}$

PSC $\mathrm{Ca}^{2+}$-response induced by Input 1

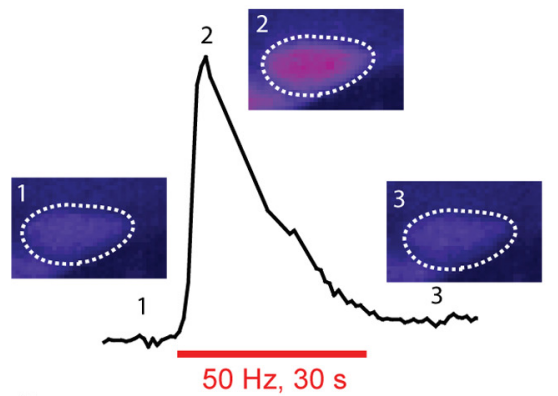

C

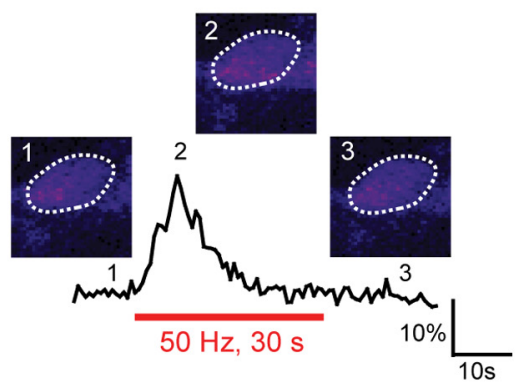

PSC $\mathrm{Ca}^{2+}$-response induced by Input 2

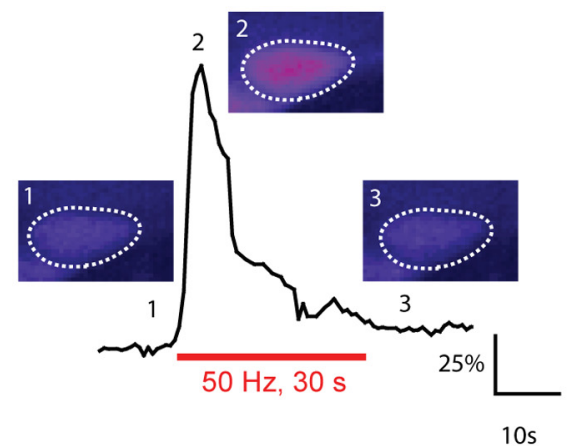

PSC $\mathrm{Ca}^{2+}$-response induced by Input 1

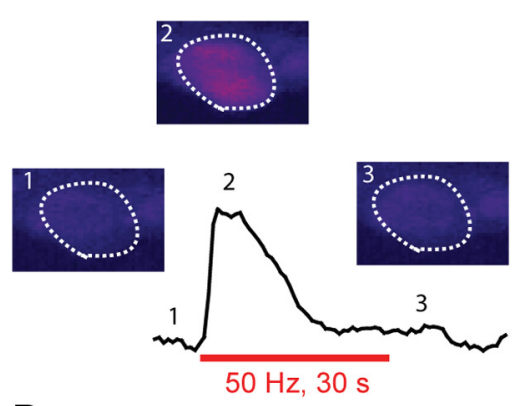

$\mathrm{D}$

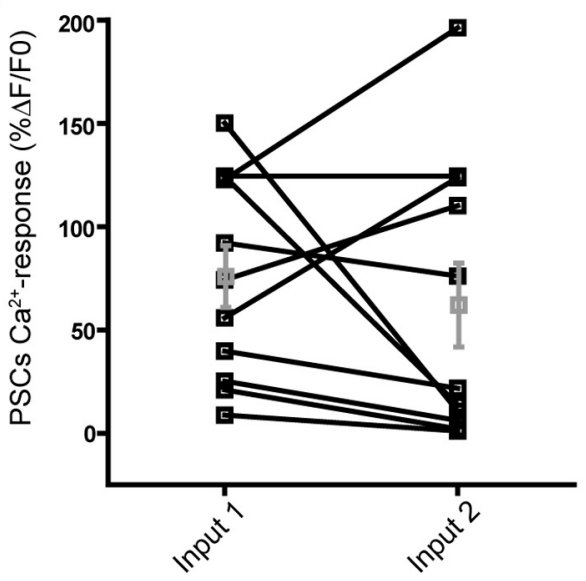

Figure 2. A single PSC detects synaptic activity of competing nerve terminals at dually innervated NMJs.A, Example of $\mathrm{Ca}^{2+}$ responses elicited in a PSC by independent stimulation of the two competing nerve terminals (Input 1 and Input 2). False color images of the changes in fluorescence of Fluo-4 illustrating $\mathrm{Ca}^{2+}$ levels before, at the peak of the response, and after the stimulation. Note that the first input (Input 1) induced a bigger $\mathrm{Ca}^{2+}$ response than the second one (Input 2). B, An example of PSC $\mathrm{Ca}^{2+}$ responses where both inputs induced similar PSC $\mathrm{Ca}^{2+}$ responses. $\boldsymbol{C}$, A third example where the first input induced a smaller PSC $\mathrm{Ca}^{2+}$ response than the second one. $\boldsymbol{D}$, Plot illustrating the diversity of PSC $\mathrm{Ca}^{2+}$ responses induced by two inputs at poly-innervated NMJs. independent neurotransmitter release from each competing input (36 PSCs of 42). The average amplitude of PSC $\mathrm{Ca}^{2+}$ response to the activity of the first input was $76.2 \pm 14.9 \% \Delta \mathrm{F} / \mathrm{F} 0$, whereas it was $62.4 \pm 20.3 \% \Delta \mathrm{F} / \mathrm{F} 0$ in response to the stimulation of the second input (Fig. 2D; $N=11$, paired $t$ test, $p>0.05$ ).

These results indicate that PSCs at dually innervated NMJs detect transmitter release from the two competing nerve terminals. As such, these results indicate that PSCs are synaptically responsive.

A single PSC decodes the synaptic strength of competing nerve terminals Although a single PSC at a dually innervated endplates responded to transmitters released by each individual nerve terminal, our data revealed a large variability in the amplitude of the responses evoked by the two terminals (Fig. 2D). Indeed, we observed that the amplitude of PSC $\mathrm{Ca}^{2+}$ responses induced by the stimulation of the first competing input was sometimes higher than those induced by the second input in $51 \%$ of the tested NMJs (Fig. $2 A$, $D$ ), similar in $25 \%$ (Fig. $2 B, D$ ) or lower in $24 \%$ (Fig. $2 C, D$ ) of the remaining responding PSCs.

One possibility might be that $\mathrm{Ca}^{2+}$ responses in PSCs reflected the level of synaptic strength of each competing terminal. This would be consistent with the properties of PSCs at mature NMJs that decode different levels of synaptic activity by producing different $\mathrm{Ca}^{2+}$ responses (Rousse et al., 2010; Todd et al., 2010). Based on the disparity in synaptic strength between competing terminals (Colman et al., 1997; Kopp et al., 2000) and the relationship between transmitter release and the responsiveness of PSCs, we hypothesized that the weaker of the competing nerve terminals would induce smaller PSC $\mathrm{Ca}^{2+}$ responses than the stronger one.

To test this hypothesis, we performed simultaneous intracellular recordings from dually innervated NMJs combined with PSCs $\mathrm{Ca}^{2+}$ imaging. Synaptic strength of each nerve terminal was determined using two approaches; the quantal content (m) using a binomial analysis of the failure rate and paired pulse facilitation (Fig. $3 A, B$ ). At dually innervated NMJs, it is known that strong inputs show bigger quantal content and smaller paired pulse facilitation than weak ones (Kopp et al., 2000). We only considered an input to be stronger than the other when its quantal content was higher and its facilitation significantly smaller than the other one (Fig. $3 A, B$ ). 
A

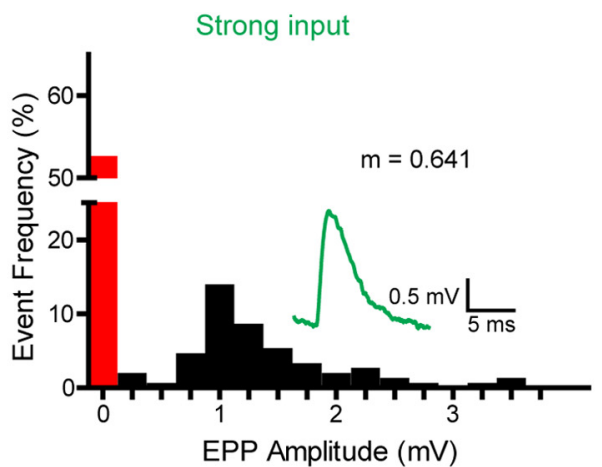

B

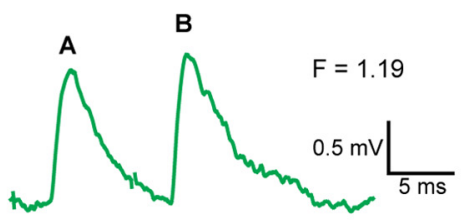

C PSC Ca ${ }^{2+}-$ response induced by the Strong input

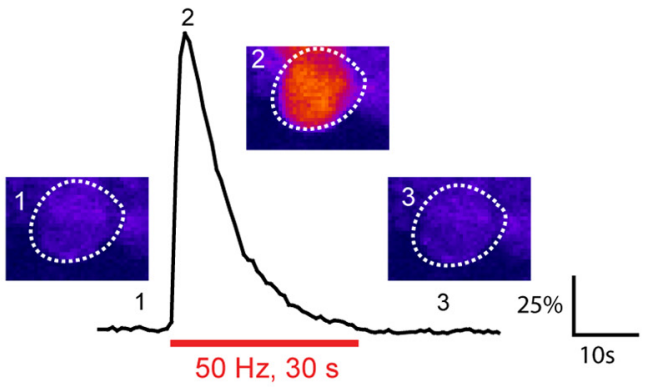

Weak input

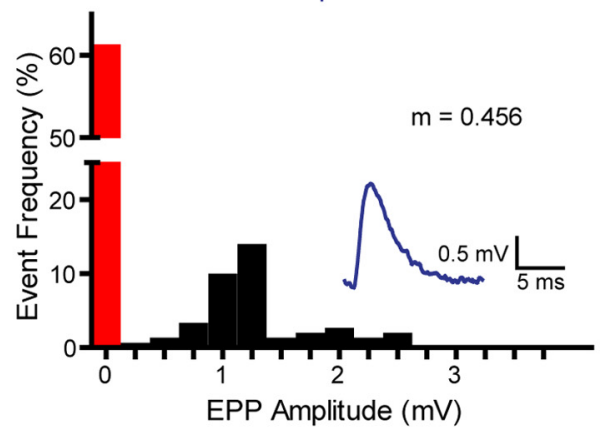

PSC $\mathrm{Ca}^{2+}$-response induced by the Weak input
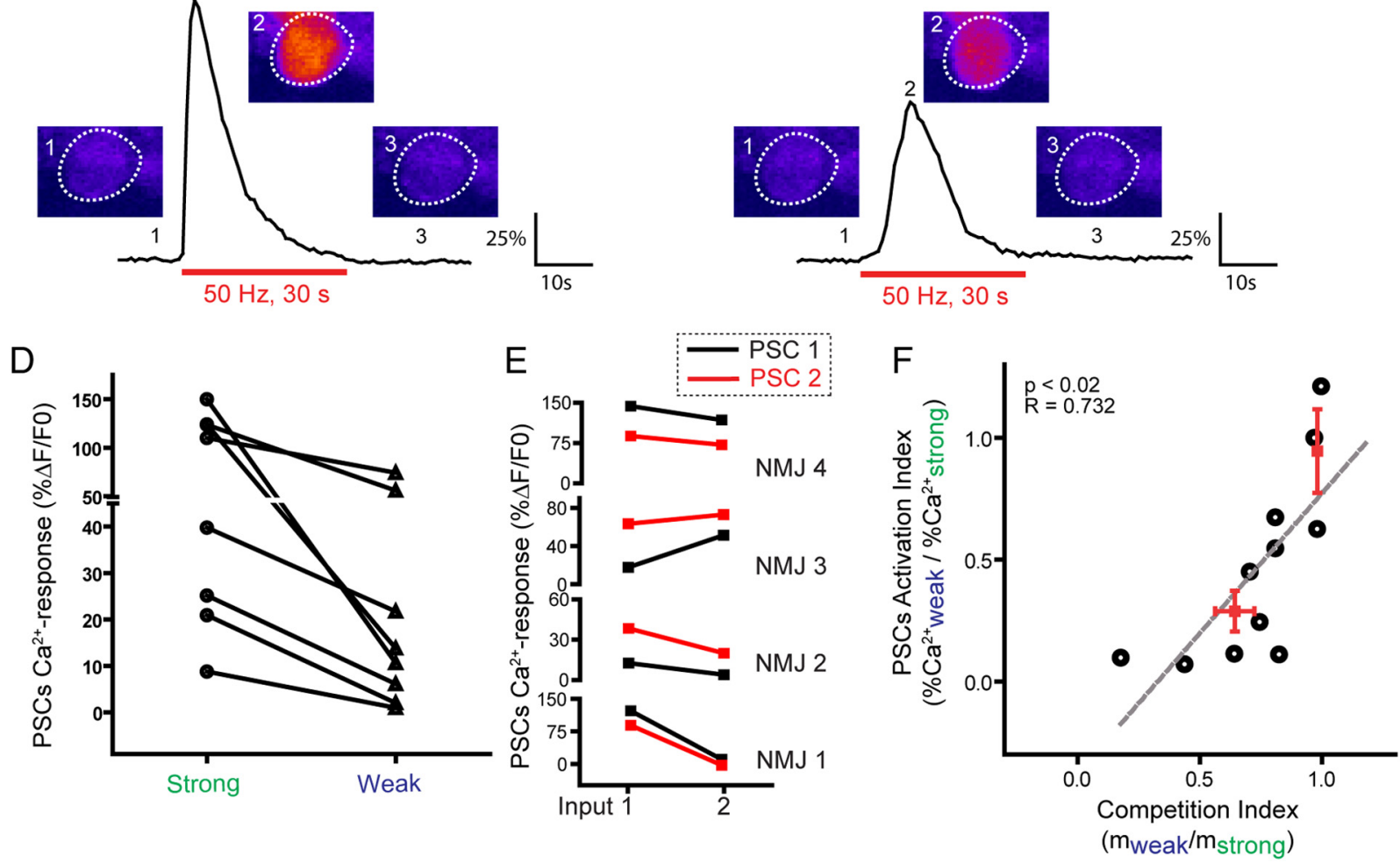

Figure 3. A single PSC decodes synaptic strength of competing nerve terminals at dually innervated NMJs. A, Distribution of EPP amplitude induced by stimulation of the strong and weak inputs, including failures. Inset, Examples of EPPs and calculated quantal content (m). $\boldsymbol{B}$, Examples of EPPs and facilitation values (F) obtained from the paired-pulse (10 ms interval) independent stimulation of strong and weak inputs shown in $A . C, \mathrm{Ca}^{2+}$ responses elicited in a PSC by independent stimulation of the strong and weak competing inputs (same as in $A$ and $B$ ). False color confocal images of changes in fluorescence of Fluo-4 illustrating $\mathrm{Ca}^{2+}$ levels before, at the peak of the response, and after stimulation. $\boldsymbol{D}$, Plot of the amplitude of PSC $\mathrm{Ca}^{2+}$ responses induced by strong (circle) and weak (triangle) terminals. PSC $\mathrm{Ca}^{2+}$ responses induced by terminals in competition at the same NMJ are connected with a black line. Note that strong inputs always induced larger $\mathrm{Ca}^{2+}$ responses than weak inputs. $E_{,} \mathrm{Ca}^{2+}$ responses induced in two PSCs at the same dually innervated NMJs. Note that the relationship between $\mathrm{Ca}^{2+}$ responses elicited by the two inputs was the same for both PSCs (black and red) at the same NMJ. $F$, Relationship between the relative synaptic strength of the competing nerve terminals (Cl, $x$-axis) and the relative responsiveness of the PSCs upon their activation by the independent activity of the competing nerve terminals (PSC activation index, $y$-axis). Each point (O) represents an individual experiment, and the red points are the average for the experiments where synaptic strength ratio was close to 1 and close to 0.5 . The strong linear relationship $(r=0.732 ; p<0.02)$ indicates that PSC responsiveness is tightly influenced by the disparity of the strength of the competing nerve terminals.

Interestingly, sustained and repeated activity of strong inputs $(50 \mathrm{~Hz}, 30 \mathrm{~s})$ always elicited larger $\mathrm{Ca}^{2+}$ responses in PSCs than the weak ones $(75.3 \pm 20.1 \% \Delta \mathrm{F} / \mathrm{F} 0$ vs $23.2 \pm 9.6 \% \Delta \mathrm{F} / \mathrm{F} 0, N=$ 8; paired $t$ test, $p=0.02$ ) (Fig. $3 C, D$ ). Importantly, stimulating the weak input before the strong one or vice-versa, did not influence the ability of PSCs to respond to the synaptic activity and did not influence the size of the $\mathrm{Ca}^{2+}$ response elicited (data not shown). As a direct corollary of this observation, one would pre- 
dict that competing inputs with similar synaptic strength at the same NMJ should trigger similar $\mathrm{Ca}^{2+}$ responses in PSCs. As expected, competing nerve terminals with similar synaptic strength (quantal content $0.32 \pm 0.06$ vs $0.33 \pm 0.06, N=4$; paired $t$ test, $p>0.05)$ showed similar PSC $\mathrm{Ca}^{2+}$ responses $(119.2 \pm 27.9 \% \Delta \mathrm{F} / \mathrm{F} 0$ vs $107.3 \pm 9.4 \% \Delta \mathrm{F} / \mathrm{F} 0, N=4$; paired $t$ test, $p>0.05)$. Interestingly, similar observations were made when two PSCs were present at dually innervated NMJs (Fig. 3E), indicating that both PSCs performed the same decoding of synaptic strength and underwent similar interactions with both competing nerve terminals.

Decoding by PSCs may be limited simply to the determination of the weakest and strongest inputs, leading to a bimodal distribution. Alternatively, it is also possible that PSCs decode the relative strength of each input, whereby a linear relationship between PSC $\mathrm{Ca}^{2+}$ responses and synaptic strength should be observed. To examine this possibility, we represented synaptic competition and the state of relative synaptic efficacy of competing nerve terminals using a competition index (CI). The CI was calculated as follows: $\mathrm{CI}=$ quantal content of weak input/quantal content of strong input.

It represented the disparity in the synaptic strength of the competing nerve terminals, a key parameter of synaptic competition. A CI of 1 indicated that the two competing terminals had similar synaptic strength, whereas a $\mathrm{CI}<1$ meant that an input was stronger than the other. We then plotted the relative PSC responsiveness to the competing nerve terminals using a PSC activation index (PAI). PAI was calculated as follows: PAI = PSC $\mathrm{Ca}^{2+}$ response induced by weak input/PSC $\mathrm{Ca}^{2+}$ response induced by strong input.

It represented the disparity in $\mathrm{PSC} \mathrm{Ca}^{2+}$ responses induced by each competing nerve terminals. A PAI of 1 indicated that the two terminals induced similar PSC $\mathrm{Ca}^{2+}$ responses, and a PAI $<1$ meant that one input induced a bigger PSC $\mathrm{Ca}^{2+}$ response than the other.

As shown in Figure $3 F$, the PAI is tightly related to the CI (linear regression, $r=0.732$; slope significantly non- $0, p<0.02$ ). Competing terminals with similar synaptic strength $(\mathrm{CI} \approx 1)$ induced similar $\mathrm{PSC} \mathrm{Ca}^{2+}$ responses $(\mathrm{PAI} \approx 1)$, whereas those with different synaptic strength $(\mathrm{CI}<1)$ induced different PSC $\mathrm{Ca}^{2+}$ responses $(\mathrm{PAI}<1)$. Importantly, the state of the competition was directly reflected in PSC responsiveness as indicated by the tight relationship between PAI and CI. Hence, these results suggest that PSC responsiveness was tightly related to the relative synaptic strength of competing terminals. Furthermore, a single PSC at a dually innervated NMJ differentiated weak and strong inputs and decoded their relative synaptic strength.

\section{Decoding by PSCs does not solely depend on neurotransmitter release}

Because of PSC sensitivity to neurotransmitter release, the difference in their responsiveness to strong and weak nerve terminals may simply be the result of the different level of transmitter release produced by each terminal. However, it is also known that the responsiveness of PSCs at adult NMJs is also in part determined by their intrinsic properties (Rousse et al., 2010). Hence, we examined whether differential PSC responses to the activity of competing nerve terminals were solely the result of the level of transmitter release or whether their intrinsic properties were adapted to each competing nerve terminal. To test this hypothesis, we increased the level of neurotransmitter released by the weak nerve terminal using a $\mathrm{K}^{+}$channel blocker, TEA ( $\left.0.5 \mathrm{~mm}\right)$. TEA did not directly alter the responsiveness of PSCs to local application of agonists (data not shown). This is consistent with the observation that PSC $\mathrm{Ca}^{2+}$ responses are not dependent on voltage-gated channels and membrane excitability but rather on G-protein coupled receptors (Robitaille, 1998; Wang et al., 2006; Rousse et al., 2010). If PSC responsiveness were solely determined by the level of transmitter release, one would predict that $\mathrm{Ca}^{2+}$ responses elicited by an increased level of transmitter release from the weak nerve terminal should evoke larger $\mathrm{Ca}^{2+}$ responses in PSCs.

We first determined in control situation the amount of transmitter released during the high-frequency stimulation because this was the synaptic activity that triggered PSC activation. We calculated the cumulative quantal release of neurotransmitters by strong and weak competing inputs during the high-frequency stimulation (HFS; $50 \mathrm{~Hz}, 30 \mathrm{~s}$ ): EPP amplitude (\% Ctrl) $\times$ quantal content, at each time point during the HFS. As expected, the strongest input had a higher cumulative quantal release than the weakest one, suggesting that more neurotransmitter was released (Fig. 4A-C). At the end of the HFS (time $30 \mathrm{~s}$ ), the strongest input had a cumulative quantal release of $289.9 \pm 40.8$, which was significantly higher than the cumulative quantal release of the weakest input (161.9 $\pm 18.1, N=4$; paired $t$ test, $p<0.05)$. Importantly, this difference was noticeable early during the HFS, a period during which PSC activation took place. Indeed, the strongest input had a cumulative quantal release of $35 . \pm 5.1$ after the first $3 \mathrm{~s}$, which was significantly higher than the one of the weakest input $(21.5 \pm 2.3, N=4$; paired $t$ test, $p<0.05$, Fig. $4 C)$. Also, as shown before, the strong input that released more neurotransmitter induced larger PSC $\mathrm{Ca}^{2+}$ responses than the weak input (strong: $127.0 \pm 8.3 \% \Delta \mathrm{F} / \mathrm{F} 0$ vs weak: $38.6 \pm 15.7 \% \Delta \mathrm{F} / \mathrm{F} 0$; $N=4$; paired $t$ test $p<0.05$ ).

In another set of experiments, we determined the basal level of quantal release and synaptic strength of competing nerve terminals; and then, the strong input was stimulated (HFS; $50 \mathrm{~Hz}$, $30 \mathrm{~s}$ ), monitored PSC $\mathrm{Ca}^{2+}$ responses, and calculated the cumulative quantal release of neurotransmitters (Fig. $4 F$ ). Then, TEA $(0.5 \mathrm{~mm})$ was bath applied, and changes in transmitter release of the weak terminal were monitored. As shown in Figure $4 D$, bath application of TEA potentiated transmitter release of the weak nerve terminal to $189.1 \pm 31.6 \%$ of control after $20 \min (N=4$ paired $t$ test, $p<0.05)$. TEA raised the quantal content of the weak nerve terminal from $0.11 \pm 0.03$ to $0.59 \pm 0.17(N=4$; paired $t$ test, $p<0.05$ ), a level that was no longer significantly smaller than the one of the nonpotentiated strong nerve terminal. The cumulative quantal release from the weak TEA-potentiated input was not different from the strong input in absence of TEA (strong: $375.3 \pm 73.76$ vs weak + TEA: $427.1 \pm 92.19 ; N=4$; paired $t$ test, $p>0.05$, Fig. $4 E-G)$.

If decoding by PSCs solely depended on the amount of neurotransmitters released, the potentiated weak input should have induced larger PSC $\mathrm{Ca}^{2+}$ responses. However, as shown in Figure $4 F, G$, average amplitude of PSCs $\mathrm{Ca}^{2+}$ responses induced by neurotransmitters released from the potentiated weak terminals was $25.7 \pm 11.0 \% \Delta \mathrm{F} / \mathrm{F} 0$, which remained significantly lower than those induced by the strong terminals in the absence of TEA $(45.1 \pm 13.4 \% \Delta \mathrm{F} / \mathrm{F} 0, N=4$; paired $t$ test, $p<0.05)$. These data indicate that increasing neurotransmission from the weak input did not alter the amplitude of PSC $\mathrm{Ca}^{2+}$ responses. Similar results were obtained when potentiating the strong input (data not shown). Thus, this strongly suggests that decoding of synaptic competition by PSCs did not solely depend on the amount of neurotransmitter released but relied also on their intrinsic properties. 
A Synaptic activity (EPPs)
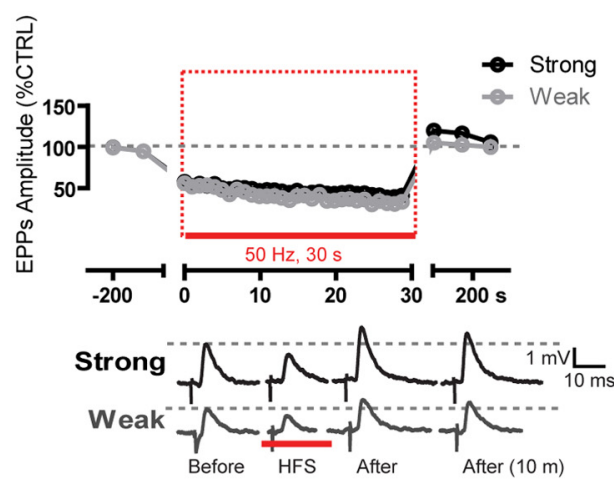

B

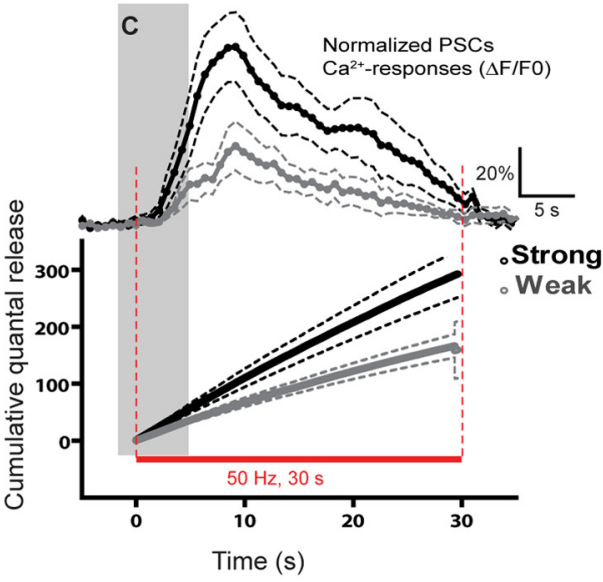

$\mathrm{D}$

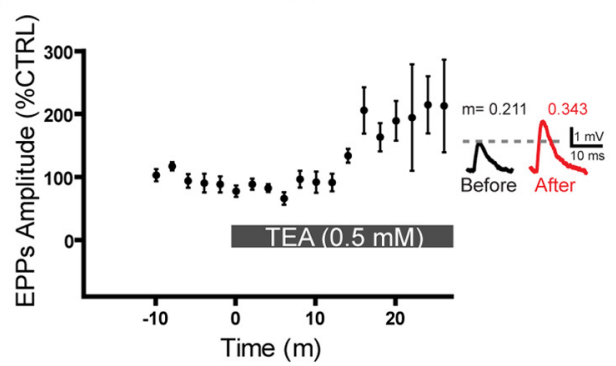

$\mathrm{F}$

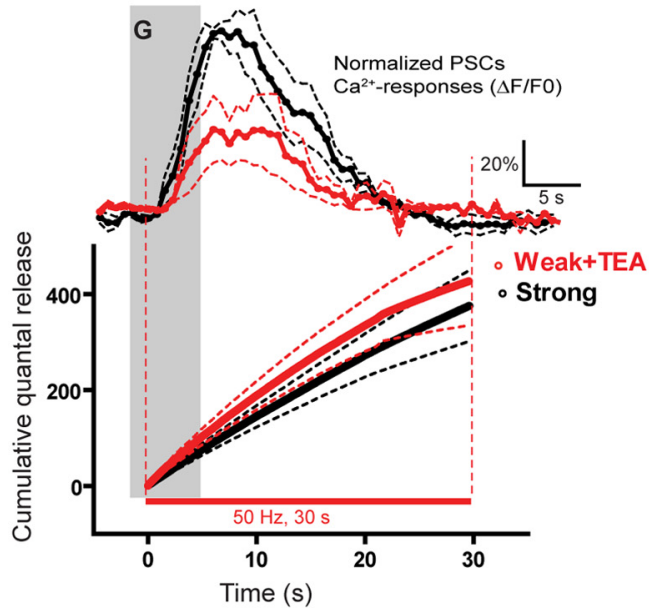

C

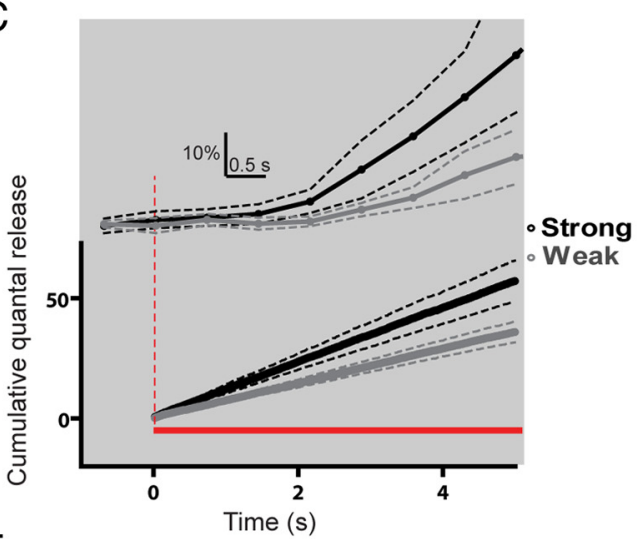

E Synaptic activity (EPPs)
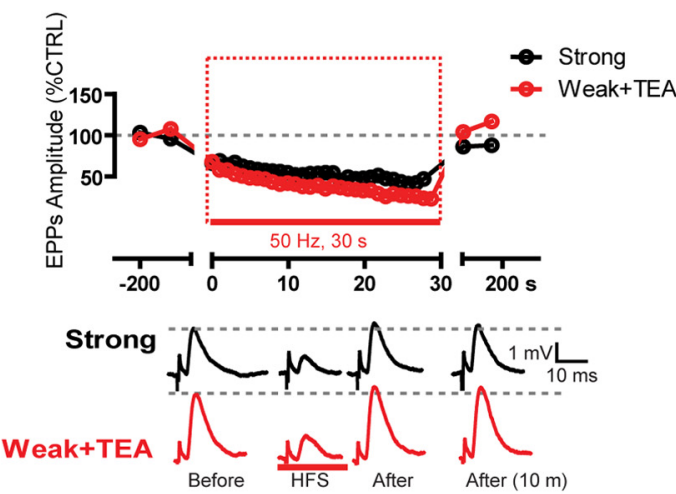

G

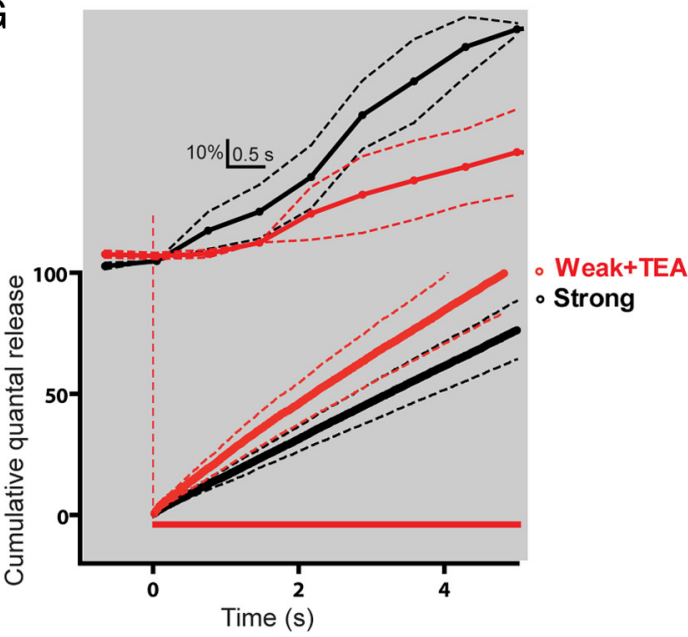

Figure 4. PSC Ca ${ }^{2+}$ responses do not solely depend on the amount of neurotransmitters released. $A$, Top, Changes in EPP amplitude before, during, and after motor nerve stimulation (red bar) of the strong (black) and weak (gray) competing inputs at the same NMJ. Period of high-frequency stimulation used to elicit PSCs $\mathrm{Ca}^{2+}$ responses is highlighted (red rectangle). (Figure legend continues.) 


\section{A single PSC decodes the synaptic strength of competing nerve terminals via functionally segregated sets of receptors}

We next examined the mechanisms by which a single PSC selectively detected and decoded ongoing synaptic competition, which could be part of PSC intrinsic properties. It has been shown that competing presynaptic terminals are spatially separated and facing their own pool of postsynaptic nicotinic receptors (Gan and Lichtman, 1998; Keller-Peck et al., 2001; Walsh and Lichtman, 2003; Wyatt and Balice-Gordon, 2003; Bishop et al., 2004). We tested whether PSCs used also dedicated pools of receptors to differentiate competing inputs. We used the properties of PSC receptor desensitization known to occur at mature NMJs. PSC receptor desensitization caused a reduction of the amplitude of $\mathrm{Ca}^{2+}$ responses at the same PSC when elicited by two series of sustained synaptic activity at interval of $20 \mathrm{~min}$ (Rochon et al., 2001). Hence, one would predict that a rundown of the $\mathrm{Ca}^{2+}$ response would be observed if PSCs used the same sets of receptors to detect the activity of competing nerve terminals.

First, we examined whether a rundown of $\mathrm{Ca}^{2+}$ responses was observed at PSCs of dually innervated NMJs by stimulating the same nerve terminal twice at $20 \mathrm{~min}$ interval and monitoring $\mathrm{Ca}^{2+}$ responses in the PSC. If PSCs at immature NMJs expressed the same property as in the adult, one would expect to see a rundown of the $\mathrm{Ca}^{2+}$ response, with the amplitude of the response evoked by the second stimulation being smaller than the first one. As shown in Figure $5 A, D$, a rundown was indeed observed in PSC $\mathrm{Ca}^{2+}$ responses where the amplitude to a second motor nerve stimulation was significantly smaller than the first one (first stimulation, $37.5 \pm 16.4 \% \Delta \mathrm{F} / \mathrm{F} 0$ vs second stimulation, $14.1 \pm 11.1 \% \Delta \mathrm{F} / \mathrm{F} 0, N=5$; paired $t$ test, $p=0.02$ ). Importantly, the rundown of the PSC $\mathrm{Ca}^{2+}$ response cannot be attributed to a decrease in neurotransmission. Indeed, Figure $5 B$ shows that EPP amplitude evoked during the first and second HFS was not significantly different (normalized EPP amplitude: first stimulation, $58.60 \pm 7.53 \%$ vs second stimulation, $66.09 \pm$ $8.37 \%, N=5$; paired $t$ test, $p>0.05)$.

$\leftarrow$

(Figure legend continued.) Bottom, Examples of EPPs induced by stimulation of strong and weak inputs before, during, and after high-frequency stimulation. $B$, Cumulative quantal release \pm SEM (dotted lines) obtained during the high-frequency stimulation (red box in A) of strong (black) and weak inputs (gray) at dually innervated NMJs. Top, Corresponding average PSC $\mathrm{Ca}^{2+}$ responses \pm SEM (dotted lines) induced by synaptic activity of weak (gray) and strong (black) inputs. $\mathrm{Ca}^{2+}$ responses are temporally aligned with the timing of the synaptic activity. Note that the strong input had a higher cumulative quantal release and evoked larger $\mathrm{PSCCa}^{2+}$ responses. The gray zone frames the part illustrated in C.C, Similar representation as in $\boldsymbol{B}$, but illustrating the first $5 \mathrm{~s}$ of the stimulation period to emphasize the different kinetics of transmitter release and PSC responses at the onset of activity. $D$, Effect of TEA $(0.5 \mathrm{~mm})$ bath application on EPP amplitude of weak inputs at dually innervated NMJs. Inset, Examples of EPPs and the calculated quantal content $(\mathrm{m})$ before and during TEA application. Note that TEA increased both EPP amplitude and quantal content of weak terminals. $\boldsymbol{E}$, Top, Changes in EPP amplitude before, during, and after motor nerve stimulation (red bar) for the strong (black) and weak TEA-potentiated (red) competing inputs of the same NMJ. The period of high-frequency stimulation eliciting PSC $\mathrm{Ca}^{2+}$ responses is highlighted (red rectangle). Bottom, Examples of EPPs induced by the stimulation of strong and weak inputs before, during, and after highfrequency stimulation. $\boldsymbol{F}$, Cumulative quantal release \pm SEM (dotted lines) obtained during high-frequency stimulation (red rectangle in E) of weak TEA-potentiated (red) and strong inputs (black) at dually innervated NMJs. Transmitter release of the weak nerve terminal was potentiated by TEA $(0.5 \mathrm{~mm})$ so that it was similar or even slightly larger than the levels observed at nonpotentiated strong inputs. Top, Average of the corresponding PSC $\mathrm{Ca}^{2+}$ responses \pm SEM (dotted lines) induced by synaptic activity of the unchanged strong (black) and the weak potentiated input by TEA (red). Note that PSC $\mathrm{Ca}^{2+}$ responses triggered by potentiated weak input were still smaller than those triggered by the nonpotentiated strong input. The gray zone frames the part of the figure illustrated in $\boldsymbol{G}$. $\boldsymbol{G}$, Similar representation as in $\boldsymbol{F}$, but illustrating the first $5 \mathrm{~s}$ of the stimulation period.
The rundown of PSC $\mathrm{Ca}^{2+}$ responses should not be observed with alternate sequential stimulation of each input whether a PSC decoded synaptic strength of the two competing terminals via different sets of receptors. In this specific set of experiments, we only studied dually innervated NMJs where competing terminals had similar synaptic strength to avoid any variability in PSC responses because of differences in synaptic strength of the terminals. As shown in Figure $5 C, D$, no rundown in PSC $\mathrm{Ca}^{2+}$ response was observed when alternate stimulation of the two competing nerve terminals was performed. The amplitude of the first $\mathrm{Ca}^{2+}$ response was $119.2 \pm 27.9 \% \Delta \mathrm{F} / \mathrm{F} 0$, whereas the amplitude of the response elicited $20 \mathrm{~min}$ later by stimulating the second nerve terminal was $107.3 \pm 9.4 \% \Delta \mathrm{F} / \mathrm{F} 0$ (Fig. $5 C, N=4$; paired $t$ test, $p>0.05$ ). These results suggest that a single PSC detected neurotransmitter release and decoded synaptic strength of the competing nerve terminals via functionally segregated sets of receptors.

\section{PSCs activation is not mediated by muscarinic receptors}

One possible mechanism that might explain the difference in the responsiveness of PSCs to weak and strong nerve terminals was that PSCs used different types of receptors for each competing input. At adult NMJs, it is known that PSC $\mathrm{Ca}^{2+}$ responses are mediated by cholinergic and purinergic receptors activated by the presynaptic release of ACh and ATP during synaptic activity (Robitaille, 1995; Rochon et al., 2001). We used selective antagonist for each receptor type to test their relative contribution to the activation of PSCs by the competing terminals. Because of the rundown of $\mathrm{Ca}^{2+}$ responses, amplitude of responses elicited by the strong and weak terminals presented in Figure $3 C, D$ was used as control.

We first tested the contribution of muscarinic receptors (mAChR) because they are the main receptor system through which PSCs are activated in adult NMJs (Rochon et al., 2001). To test the contribution of these receptors in the decoding of synaptic strength by PSCs, we stimulated independently each of the competing terminals in the presence of the general muscarinic receptor antagonist atropine $(60 \mu \mathrm{M})$ applied in the bath. Atropine is known to block synaptic-dependent activation of PSCs of adult mammalian NMJs (Rochon et al., 2001). Surprisingly, atropine had no effect on PSC $\mathrm{Ca}^{2+}$ responses induced by the stimulation of the strong or weak input (Fig. $6 A, C$ ). Indeed, the amplitude of PSC $\mathrm{Ca}^{2+}$ responses induced by neurotransmission from the strong input in the presence of atropine was not different from control $(70.5 \pm 22.1 \% \Delta \mathrm{F} / \mathrm{F} 0$ in atropine, $N=4$ vs $75.3 \pm 20.1 \% \Delta \mathrm{F} / \mathrm{F} 0$ in control, $N=8$; one-way Kruskal-Wallis ANOVA test, Dunn's Multiple-Comparison post-test, $p>0.05$ ). This was also the case for PSC $\mathrm{Ca}^{2+}$ responses induced by neurotransmission from the weak input where no significant difference was noticed $(37.6 \pm 18.8 \% \Delta \mathrm{F} / \mathrm{F} 0$ in atropine, $N=4$ vs $26.3 \pm 10.4 \% \Delta \mathrm{F} / \mathrm{F} 0$ in control, $N=7$; one-way Kruskal-Wallis ANOVA test, Dunn's Multiple-Comparison post-test, $p>0.05$ ). Similar results were obtained with scopolamine, another large spectrum muscarinic antagonist (data not shown).

We next examined whether the lack of contribution of $\mathrm{mAChR}$ to PSC activation was the result of the absence of functional mAChR. We tested this possibility by locally applying the $\mathrm{mAChR}$ agonist muscarine $(3 \mu \mathrm{M})$ on PSCs. As shown in Figure $6 A, C$, local application of muscarine elicited $\mathrm{PSC} \mathrm{Ca}^{2+}$ responses after atropine washout $(62.45 \pm 17.84 \% \Delta \mathrm{F} / \mathrm{F} 0, N=4)$. $\mathrm{No} \mathrm{Ca}^{2+}$ responses were induced by local muscarine application in the presence of atropine $(1.524 \pm 0.5374 \% \Delta \mathrm{F} / \mathrm{F} 0, N=4$, paired $t$ 
A Repetitive Stimulation

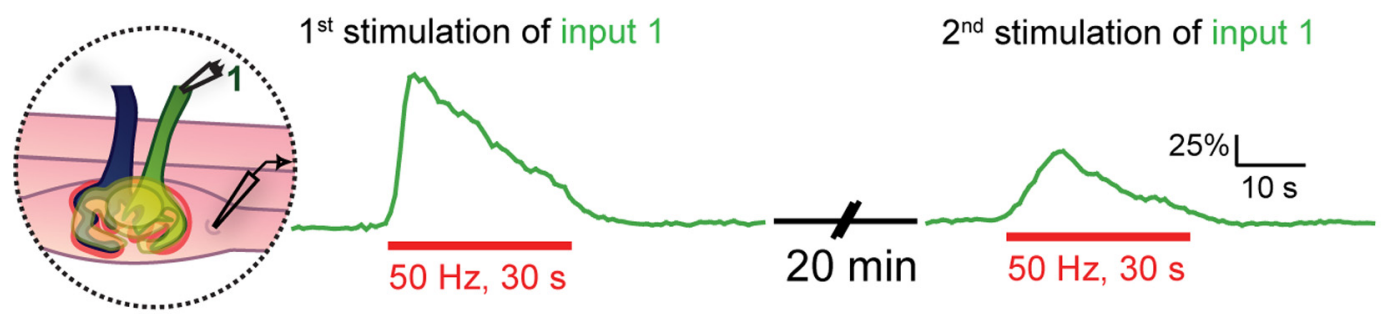

B

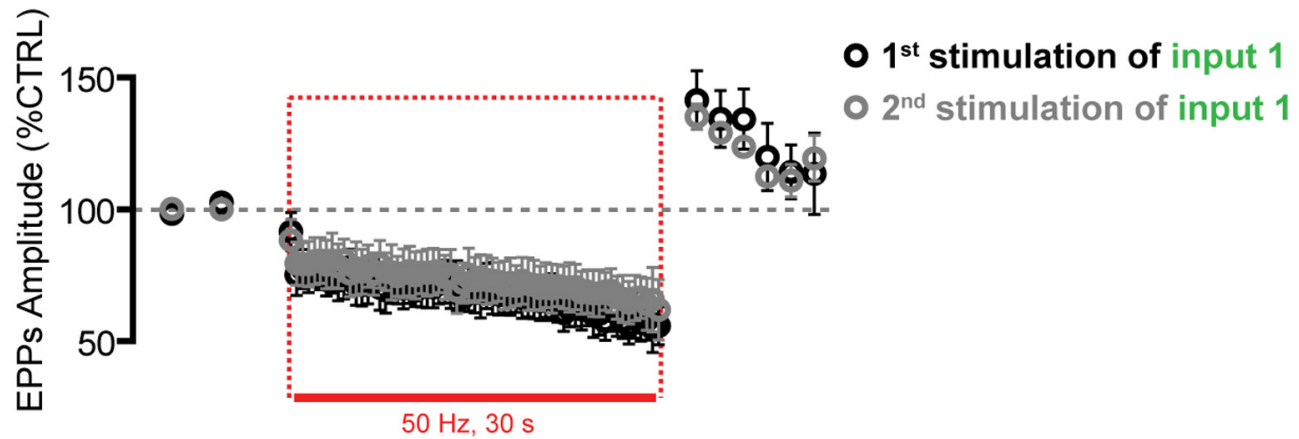

$50 \mathrm{~Hz}, 30 \mathrm{~s}$
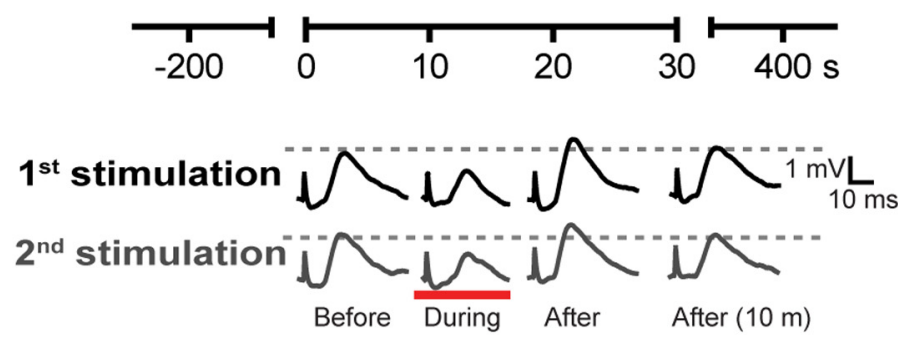

C Alternate Stimulation

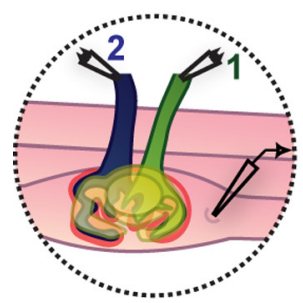

D $1^{\text {st }}$ stimulation of input 1
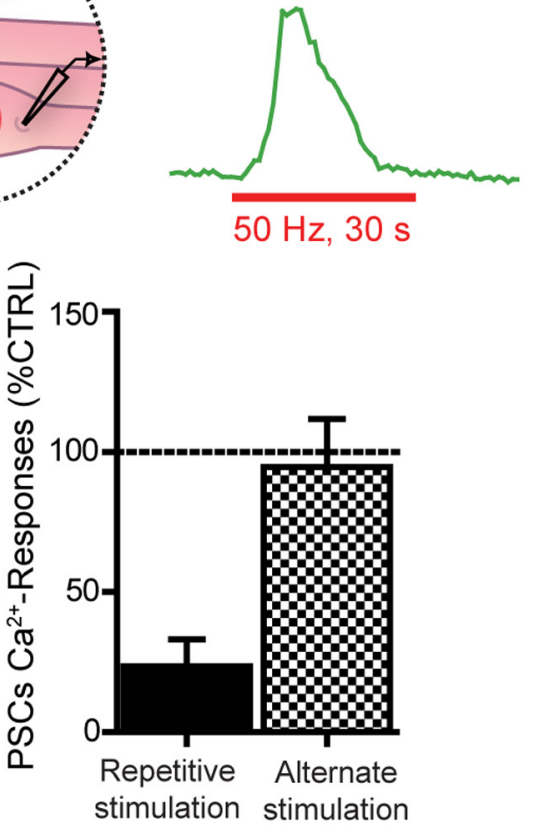

(A)

(C) $1^{\text {st }}$ stimulation of input 2
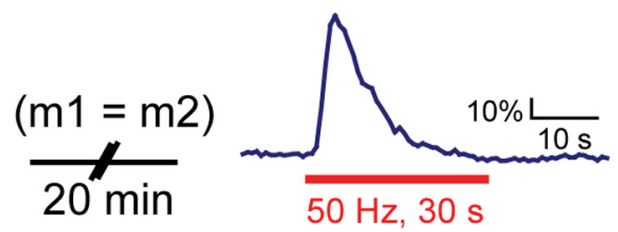

Figure 5. Rundown in PSC Ca ${ }^{2+}$ responses after repetitive stimulations. $A, \mathrm{PSCCa}^{2+}$ responses induced by the sustained stimulation of the same input (Input 1$)$. Note that the second PSC $\mathrm{Ca}^{2+}$ response induced by the second stimulation of the same input was smaller than the first one. $\boldsymbol{B}$, Top, Changes in EPP amplitude \pm SEM before, during, and after the first (Figure legend continues.) 
test, $p<0.05$, Fig. $6 C$ ), further confirming the efficiency of the muscarinic antagonist.

These results indicates that PSC mAChRs were not activated by neurotransmitter release from the strong or the weak input with the stimulation parameters used and were not required for the proper decoding of the synaptic strength by PSCs in the experimental conditions tested.

\section{PSC activation is mediated by purinergic receptors}

We next tested the contribution of purinergic receptors because synaptic ATP is known to activate PSCs via these receptors (Rochon et al., 2001; Todd and Robitaille, 2006). We stimulated independently each of the competing terminals in the presence of the general $\mathrm{P} 2_{\mathrm{Y}}$ receptor antagonist, $\mathrm{RB} 2$ (Claes et al., 2004; De Lorenzo et al., 2006), applied in the bath perfusion. As shown in Figure $6 B, C$, neither the stimulation of the strong nor the weak input elicited a detectable PSC Ca ${ }^{2+}$ response in the presence of RB2 (strong with RB2, $2.0 \pm 0.5 \% \Delta \mathrm{F} / \mathrm{F} 0, N=5$ vs control, $75.3 \pm 20.1 \% \Delta \mathrm{F} / \mathrm{F} 0 \mathrm{~N}=8$; weak with RB2, $2.0 \pm 0.6 \% \Delta \mathrm{F} / \mathrm{F} 0, N$ $=5$ vs control, $26.3 \pm 10.4 \% \Delta \mathrm{F} / \mathrm{F} 0 N=7$, one-way KruskalWallis ANOVA test, Dunn's Multiple-Comparison post-test, $p<$ 0.05, Fig. $6 C$ ). Differences in PSC $\mathrm{Ca}^{2+}$ responses induced by the stimulation of the strong or weak input were no longer noticeable because no responses were induced. Furthermore, the absence of synaptic-induced $\mathrm{Ca}^{2+}$ responses in PSCs cannot be explained by a reduction in transmitter release. Indeed, intracellular recordings showed that EPPs were still evoked by the stimulation of the strong or the weak input in the presence of RB2 (Fig. 6B). Hence, the lack of PSC Ca ${ }^{2+}$ responses was not the result of the absence of synaptic activity but the blockade of $\mathrm{P} 2$ receptors on PSCs.

The responsiveness of PSCs to ATP was further tested by local application of ATP $(5 \mu \mathrm{M})$ as the agonist. ATP did not elicit $\mathrm{Ca}^{2+}$ responses in presence of RB2 $(2.9 \pm 2.8 \% \Delta \mathrm{F} / \mathrm{F} 0, N=4)$ but fully recovered after $30 \mathrm{~min}$ of washout $(75.1 \pm 6.9 \% \Delta \mathrm{F} / \mathrm{F} 0, N=4$; paired $t$ test $p=0.0007$; washout vs RB2). Therefore, this strongly suggests that decoding of synaptic strength of competing nerve terminals by PSCs was mediated by $\mathrm{P} 2_{\mathrm{Y}}$ receptors. Together, these results show that PSCs used the same type of receptors, $\mathrm{P} 2_{\mathrm{Y}}$ receptors, to detect the activity of competing nerve terminals. Although they were present and functional, muscarinic receptors were not used for synaptic communication with PSCs at immature NMJs in the paradigm studied.

\section{Localization and distribution of P2Y receptors on PSCs}

Our data indicate that PSCs decoded synaptic competition via functionally segregated $\mathrm{P} 2_{\mathrm{Y}}$ receptors, whereas muscarinic receptors did not participate in this decoding even though they were present and functional. This differential involvement of the two receptor systems may have a morphological basis such that the purinergic receptors were preferentially associated with release

\footnotetext{
(Figure legend continued.) (black) and second (gray) nerve stimulation of the same input (Input 1). The period of high-frequency stimulation used to elicit PSCs $\mathrm{Ca}^{2+}$ responses is highlighted (red rectangle). Bottom, Examples of EPPs induced by the first and second stimulation of Input 1 before, during, and after the high-frequency stimulation. Note that EPP amplitudes induced by the first and second stimulation of the same input are similar. C, PSC Ca ${ }^{2+}$ responses induced by the alternate stimulation of Input 1 followed, 20 min later, by the stimulation of Input 2 at NMJs where both inputs had similar quantal content ( $\mathrm{m} 1$ indicates the quantal content of Input 1; and $\mathrm{m} 2$, the quantal content of Input 2). Note that $\mathrm{Ca}^{2+}$ responses from both PSCs were similar, with no evident rundown. $\boldsymbol{D}$, Histogram showing the mean of the normalized amplitude of the second $\mathrm{PSC}^{2+}{ }^{2+}$ responses in the repetitive (same input, black, $A$ ) and alternate paradigms (alternate inputs, gray, $\mathbf{C}$.
}

sites whereas muscarinic receptors were not. Hence, we performed a series of immunohistochemical labeling to determine the relative distribution of purinergic and muscarinic receptors and assessed their respective distribution in relation with presynaptic and glial markers.

We first examined the spatial distribution of $\mathrm{P} 2_{\mathrm{Y}}$ receptors at poly-innervated NMJs. Poly-innervation was confirmed by the presence of two axons innervating the same endplate, revealed by the neurofilament labeling. We focused on $\mathrm{P} 2{ }_{\mathrm{Y}} 1 \mathrm{R}$ based on the pharmacological signature of the $\mathrm{Ca}^{2+}$ responses (Robitaille, 1995; Rochon et al., 2001). As shown in Figure 7A, C, $\mathrm{P} 2_{\mathrm{Y}} 1 \mathrm{R}$ were present at poly-innervated NMJs (13 NMJs, 6 muscles). $\mathrm{P} 2_{\mathrm{Y}} 1 \mathrm{R}$ labeling was localized at the endplate area along with the presynaptic (SV2 and neurofilament) and postsynaptic ( $\alpha$-bungarotoxin) markers. Interestingly, the $\mathrm{P} 2_{\mathrm{Y}} 1 \mathrm{R}$ labeling was punctuated with puncta of different sizes and intensity distributed over the NMJ area.

We next determined with which synaptic compartment the P2Y1R labeling was associated. First, we determined whether the labeling was on the postsynaptic side of the endplate area or whether it was preferentially located in the presynaptic/PSC area. To determine this, we observed NMJs located on the side of muscle fibers. If located in the postsynaptic side, the P2Y1R labeling should be intermingled with the $\alpha$-bungarotoxin staining. However, as shown in Figure $7 B$, the $\mathrm{P} 2_{\mathrm{Y}} 1 \mathrm{R}$ labeling was located above the postsynaptic receptor staining, indicating that it was located in the presynaptic and/or PSC compartments.

Next, we used two strategies to determine whether the $\mathrm{P} 2_{\mathrm{Y}} 1 \mathrm{R}$ were preferentially located in the presynaptic elements or in the PSCs. PSCs were identified using the single-cell electroporation technique (Fig. $7 C$ ) as the $S 100 \beta$ antibody cross-reacted with the one used for labeling the $\mathrm{P} 2_{\mathrm{Y}} 1 \mathrm{R}$. First, we analyzed the distribution of $\mathrm{P} 2_{\mathrm{Y}} 1 \mathrm{R}$ puncta (green) in relation with the SV2 labeling, indicative of active zone labeling (red). If the two labels overlapped, indicative of a presynaptic localization, one should see a significant level of yellow pixels (green and red gives yellow) in the overlay image. However, whether the two labels did not overlap, the initial colors of the labels should be unaltered when overlaid. As shown in Figure 7D, E, only a few yellow hotspots were observed within the boundary of the PSCs. Interestingly, the hotspots of $\mathrm{P} 2{ }_{\mathrm{Y}} 1 \mathrm{R}$ were often juxtaposed to active zones revealed by the SV2 labeling. Second, we observed a number of $\mathrm{P} 2{ }_{\mathrm{Y}} 1 \mathrm{R}$ hotspots located at focal planes above the presynaptic labeling (Fig. $7 F$ ), probably in PSC compartments that sit on top of the presynaptic terminals. Hence, the presence of $\mathrm{P}_{\mathrm{Y}} \mathrm{Rs}$ in PSCs above the presynaptic terminals and the very poor overlap between the $\mathrm{P} 2_{\mathrm{Y}} 1 \mathrm{R}$ labeling and the presynaptic markers strongly argue that these receptors were preferentially located in PSCs, juxtaposed to the presynaptic release sites. This is consistent with their role in the detection of transmitter released by the competing nerve terminals.

\section{Localization and distribution of muscarinic receptors on PSCs}

We next examined the presence and distribution of muscarinic receptors to determine their distribution in relation with presynaptic markers. Because our data revealed that PSC functional muscarinic receptors were not required for decoding synaptic strength of competing terminals, we hypothesized that muscarinic receptors, unlike $\mathrm{P} 2_{\mathrm{Y}}$ receptors, were not in close juxtaposition with SV2 positive sites, thus limiting their activation. To test this possibility, we labeled type 3 (mAChR3) and 5 (mAChR5) muscarinic receptors to study their distribution at the NMJ. 
A PSCs $\mathrm{Ca}^{2+}$-reponses
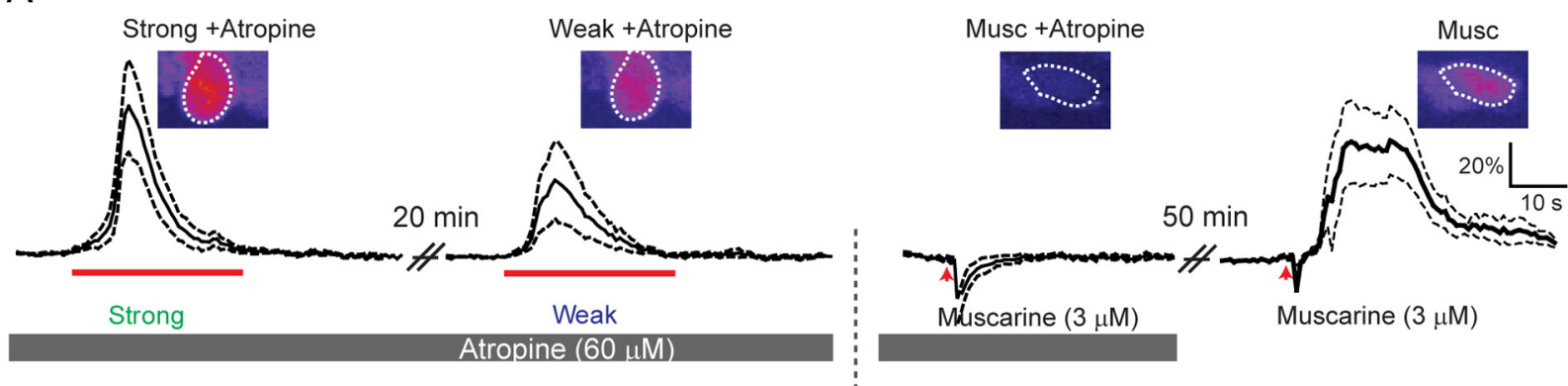

B PSCs $\mathrm{Ca}^{2+}$-reponses

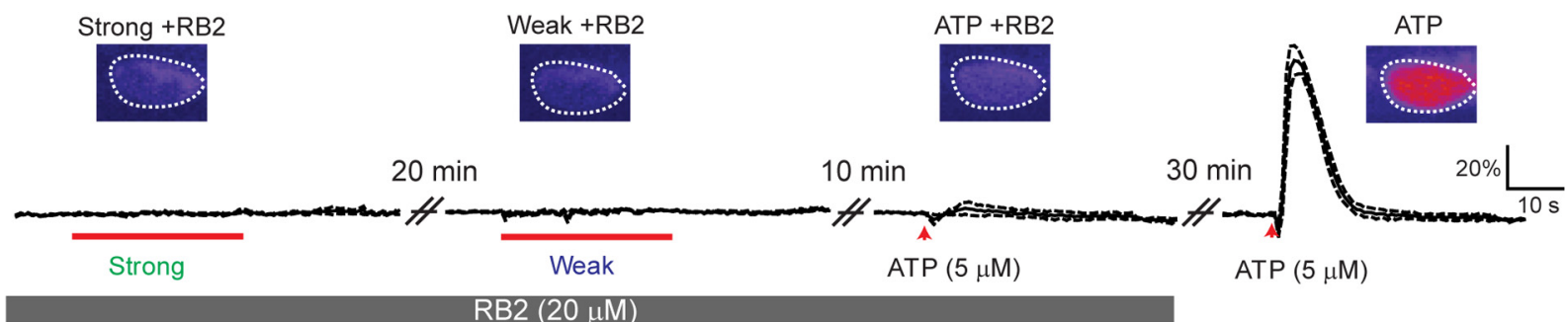

EPPs (Synaptic activity)
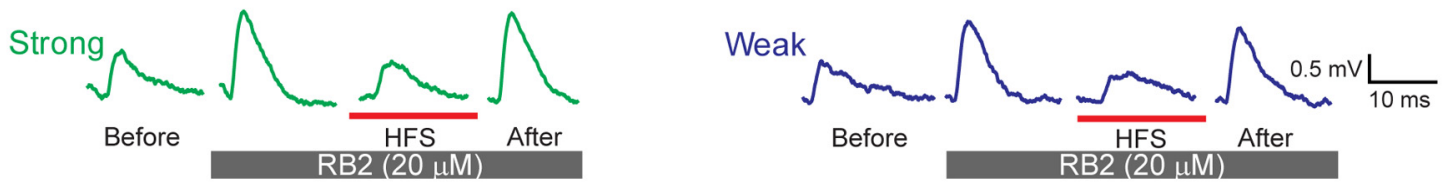

C

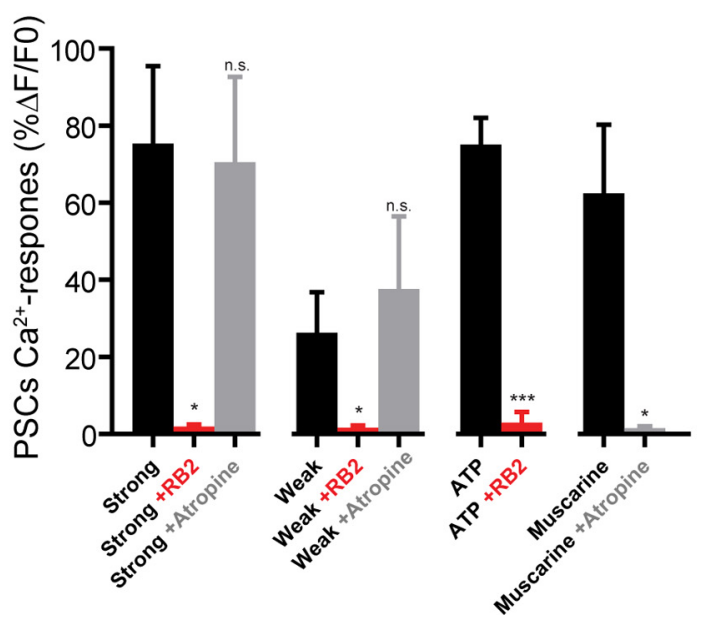

Figure 6. $\mathrm{PSCS} \mathrm{Ca}^{2+}$ responses are mediated by $\mathrm{P}_{Y}$ receptors, not muscarinic receptors. $\boldsymbol{A}, \mathrm{PSC}$ responsiveness to ventral root stimulation during bath application of the $\mathrm{mAChR}$ antagonist, atropine $(60 \mu \mathrm{M})$. Note that atropine did not prevent PSC $\mathrm{Ca}^{2+}$ responses induced by the strong and the weak input stimulations but antagonized responses induced by local application of the $\mathrm{mAChR}$ agonist, muscarine $(3 \mu \mathrm{m})$. The dark trace represents the average of PSC $\mathrm{Ca}^{2+}$ responses; and the dotted lines represent SEM. Inset, False color confocal images showing changes in fluorescence of Fluo-4 at the peak of the response. $B$, Top, PSC $\mathrm{Ca}^{2+}$ activity evoked in the presence of the P2 receptor antagonist, $\mathrm{RB} 2(20 \mu \mathrm{m})$. Note that no $\mathrm{Ca}^{2+}$ responses were evoked in the presence of RB2 either by stimulation of the strong or the weak input. Also, responses induced by local application of the P2 receptor agonist, ATP ( $3 \mu \mathrm{M})$, were antagonized. Bottom, Examples of EPPs induced by the strong and weak inputs before and during RB2 application. Note that the lack of PSC $\mathrm{Ca}^{2+}$ responses cannot be attributed to the absence of synaptic activity because EPPs were still elicited by motor nerve stimulation. C, Histogram showing PSC $\mathrm{Ca}^{2+}$ responses induced by strong and weak inputs and local application of agonists in the different conditions studied.

As shown in Figure 8, these receptors were present at the NMJ, as revealed by their immunolabeling associated with presynaptic and postsynaptic markers. Similarly to $\mathrm{P}_{\mathrm{Y}} 1$ receptors, muscarinic receptors were not found in the postsynaptic compartment as indicated by the distribution of the labeling located above the $\alpha$-bungarotoxin staining observed on NMJs located on the side of the muscle fiber (Fig. 8B).

We next examined the muscarinic receptor distribution to determine whether they were clustered in hotspots. As shown in
Figure $8 C, D$, even though hotspots and clustering of receptors were sometimes observed, the labeling of mAChR5 and mAChR3 was mostly unstructured (14 NMJs, 5 muscles for mAChR5; 11 NMJs, 4 muscles for mAChR3), presenting a more uniform and even distribution throughout the area of the NMJ. This is similar to what has been reported for muscarinic receptors distribution at NMJs of newborn rats (Garcia et al., 2005). This uniformity in the receptor labeling prevented further characterization of the localization of the synaptic compartments in which they were 
A

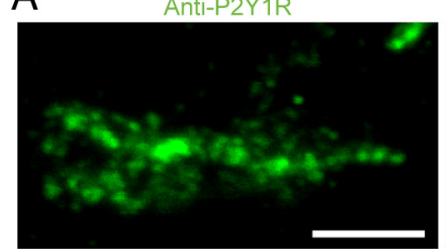

B

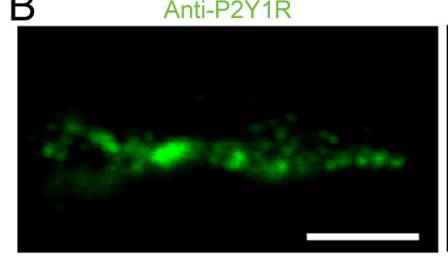

C

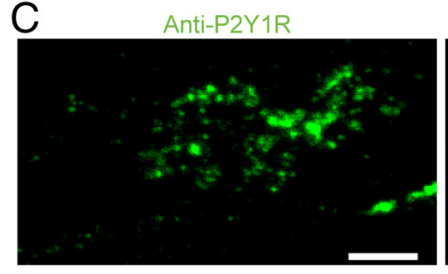

D

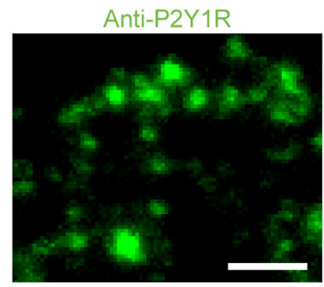

E

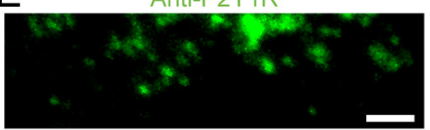

F

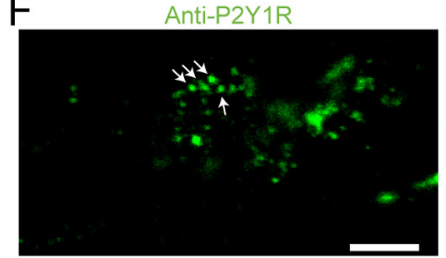

$\alpha$-Bungarotoxin

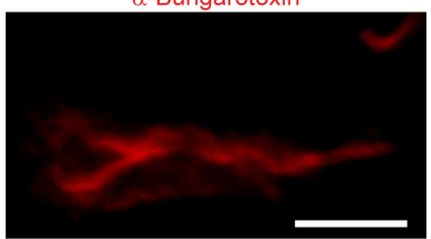

$\alpha$-Bungarotoxin

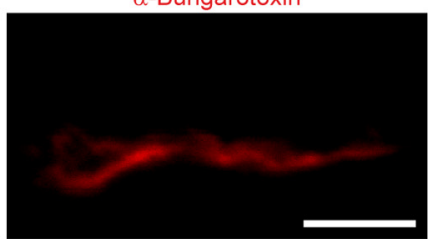

Anti-NFM-SV2

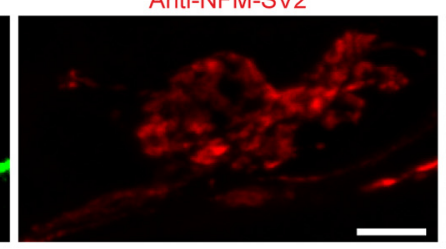

Anti-NFM-SV2

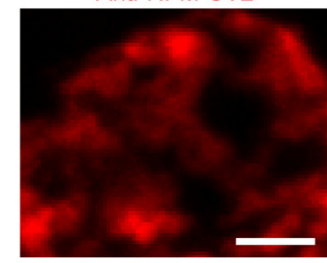

Anti-NFM-SV2

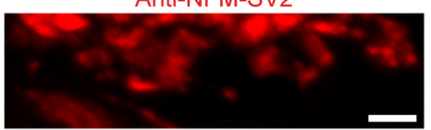

Anti-NFM-SV2

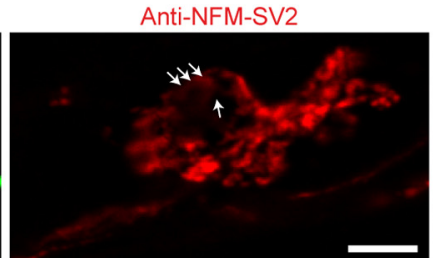

Anti-NFM-SV2

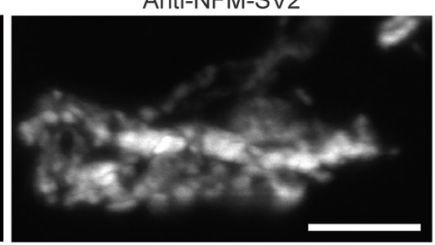

$\alpha$-Bungarotoxin + Anti-P2Y1R

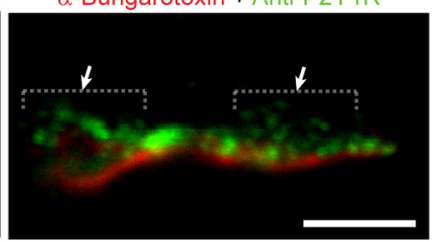

Labeled PSCs

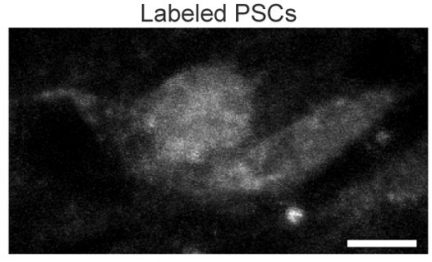

Labeled PSCs

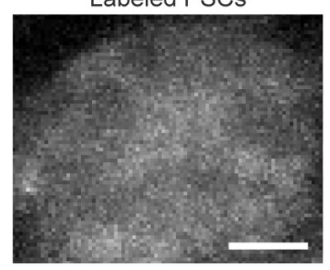

Labeled PSCs

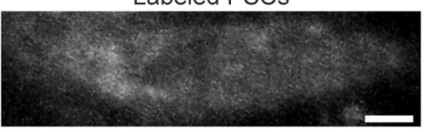

Labeled PSCs

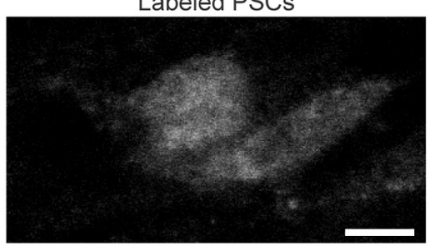

Merge

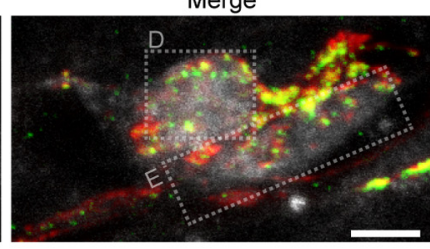

Anti-P2Y1R + Anti-NFM-SV2

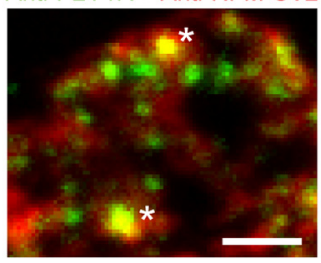

Anti-P2Y1R + Anti-NFM-SV2

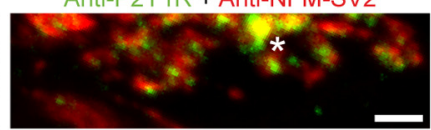

Merge

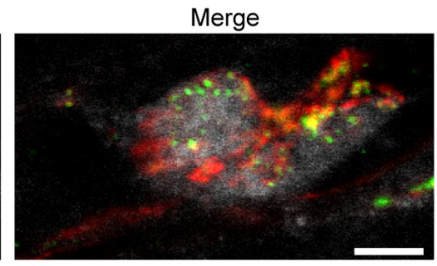

Figure 7. $P 2_{\gamma} 1 R s$ at poly-innervated NMJs. $A$, $z$-stack of false color of 9 confocal images of immunohistochemical labeling of type $1 \mathrm{P}_{\gamma}$ receptors $\left(P 2_{\gamma} 1 R\right.$; green), postsynaptic $n A C h R s$ ( $\alpha$-bungarotoxin; red), and presynaptic terminals (NF-SV2; gray) at a P7 poly-innervated NMJ. Note that P2 1 1Rs were arranged in "hotspots," with a punctuated distribution throughout the endplate area (in red). $\boldsymbol{B}, A$ single focal plane of the NMJ presented in $\boldsymbol{A}$ showing $\mathrm{P} 2_{\gamma} 1 \mathrm{Rs}$ (green) and postsynaptic nAChRs (red). Note that $P 2_{\gamma} 1 \mathrm{Rs}$ and nAChRs are located at a different level and do not colocalize (dashed lines and arrows represent 2 regions where P2Y1R and nAChR did not overlap). C, Confocal $z$-stack of 5 images of en face view of a P7 poly-innervated NMJ showing P2 $1 \mathrm{P}$ (green), presynaptic terminals (NF-SV2; red), and dextran-loaded PSCs (gray). Note that P2 21 lR labeling was present in the area of the dextran-loaded PSCs. Dotted boxes in the right panel highlight the regions enlarged in $\boldsymbol{D}$ and $\boldsymbol{E}$. D, Higher magnification of a part of the NMJ presented in C. Note the puncta of P2 1 Rs (green) over the area of the PSCs, interspersed in between presynaptic labeling and closely associated with presynaptic active zones (NF-SV2; red). Note also that very few $\mathrm{P}_{\gamma} \mathrm{\gamma}$ hotspots colocalized with presynaptic elements (yellow spots, asterisks in right panel). $\boldsymbol{E}$, Same as in $\boldsymbol{D}$ but illustrating the $\boldsymbol{E}$ dotted box highlighted in $\boldsymbol{C}$. $\boldsymbol{F}$, An image of a single plane focusing on the top of the NMJ showing hotspots of P2 $1 \mathrm{R}$ (green) localized within the dextran-loaded PSC (gray) where the presynaptic staining (NF-SV2; red) was out of focus (arrows). Scale bars: $\boldsymbol{A}-\boldsymbol{C}, \boldsymbol{F}, 5 \mu \mathrm{m} ; \boldsymbol{D}, \boldsymbol{E}, 2 \mu \mathrm{m}$.

present. Hence, these data suggest that the muscarinic receptors, unlike $\mathrm{P} 2_{\mathrm{Y}} 1$ Rs, were not specifically associated with active zones.

\section{Is there a territorial distribution of $\mathrm{P} 2_{\mathrm{Y}}$ receptors?}

We finally examined the overall distribution of $\mathrm{P} 2{ }_{\mathrm{Y}} \mathrm{R}$ to determine whether the decoding of the strong and weak inputs by PSCs could be explained by a preferential association of the $\mathrm{P} 2{ }_{\mathrm{Y}} \mathrm{R}$ with the strong nerve terminal. Knowing that competing nerve terminals can occupy defined territories, we postulated that the overall distribution of $\mathrm{P} 2{ }_{\mathrm{Y}} \mathrm{R}$ should reflect this territorial organization, resulting in a preferential accumulation of $\mathrm{P} 2_{\mathrm{Y}} \mathrm{R}$ hotspots on a portion of the PSC, presumably reflecting the nerve terminal territories.

As shown in Figure 9A, it was indeed possible to observe such uneven distribution of $\mathrm{P} 2{ }_{\mathrm{Y}} \mathrm{Rs}$ whereby some areas showed more numerous and/or brighter hotspots than another area of the poly-innervated NMJ. However, we also observed examples where the overall distribution of $\mathrm{P} 2{ }_{\mathrm{Y}} \mathrm{Rs}$ hotspots was more evenly spread (Fig. 9B). These results may reflect the variability in the strength of the competing nerve terminals.

To ascertain this possibility, we examined the distribution of $\mathrm{P} 2{ }_{\mathrm{Y}}$ Rs at mono-innervated NMJs as it could not be influenced by 
A

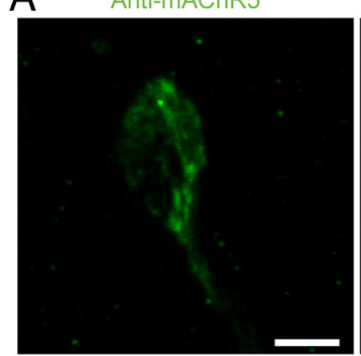

B

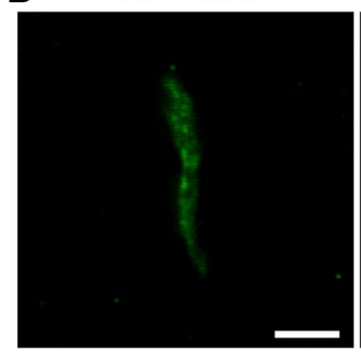

C

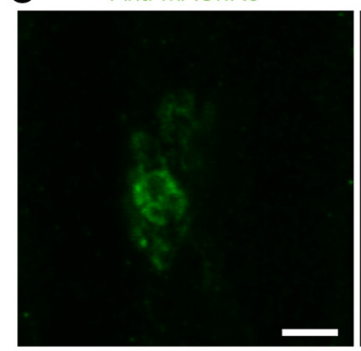

D Anti-mAChR3

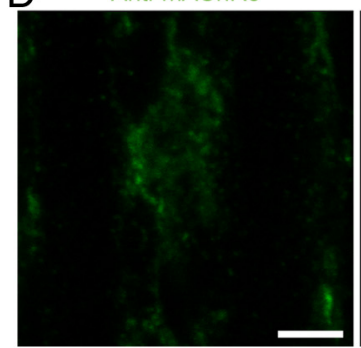

$\alpha$-Bungarotoxin

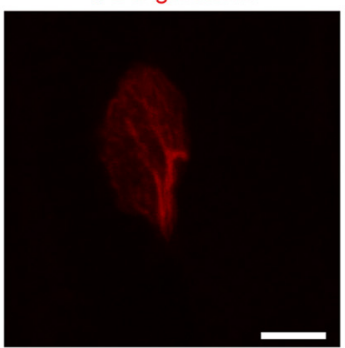

$\alpha$-Bungarotoxin

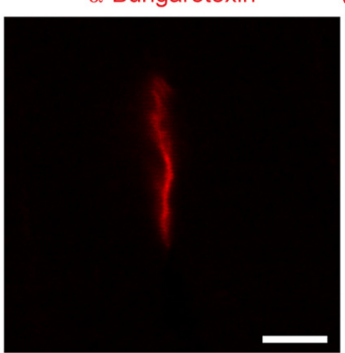

$\alpha$-Bungarotoxin

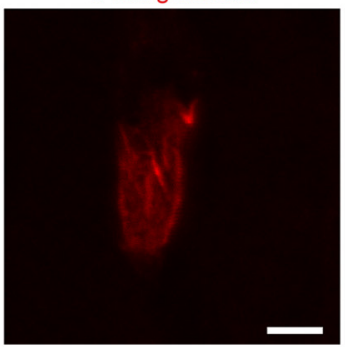

$\alpha$-Bungarotoxin

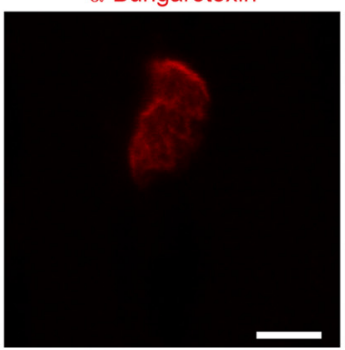

Anti-NFM-SV2

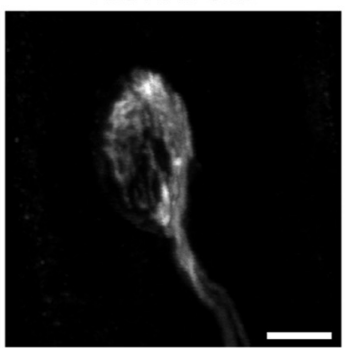

$\alpha$-Bungarotoxin + Anti-mAChR5

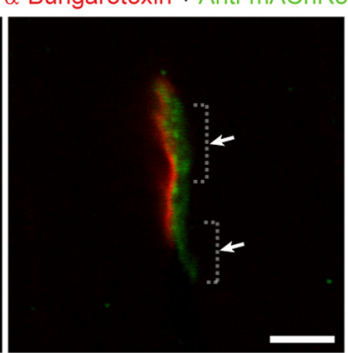

Anti-NFM-SV2

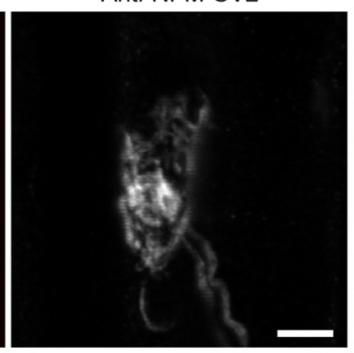

Anti-NFM-SV2

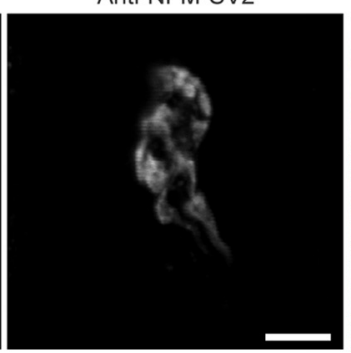

$S 100 \beta$

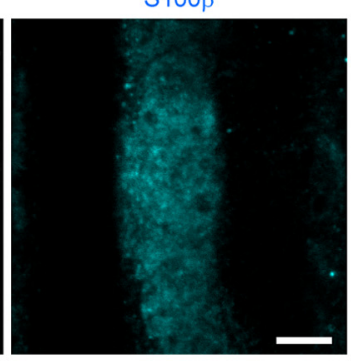

$\mathrm{S} 100 \beta$

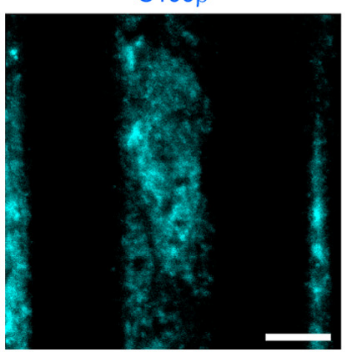

Merge

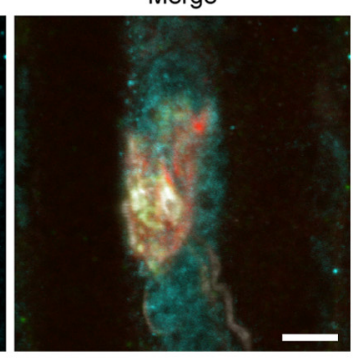

Merge

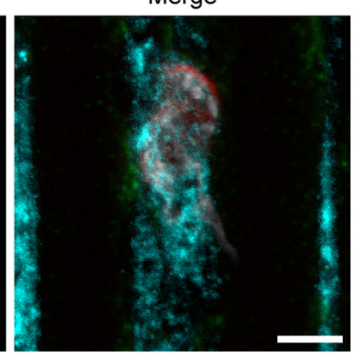

Figure 8. Type 5 and Type $3 \mathrm{mAChRs}$ at poly-innervated NMJs. A, False color confocal $z$-stack of 10 images of immunohistochemical labeling of Type $5 \mathrm{mAChRs}$ ( $\mathrm{mAChR5}$; green), postsynaptic nAChRs ( $\alpha$-bungarotoxin; red), and presynaptic terminals (NF-SV2; gray) at a P7 poly-innervated NMJ. Note the diffuse organization of mAChR5 that covers most of the endplate area in red. $\boldsymbol{B}, \mathrm{A}$ single focal plane of the NMJ presented in $\boldsymbol{A}$ showing mAChR5 (green) and postsynaptic nAChRs (red). Note that mAChR5 and nAChR were located at a different level and did not colocalize (hyphenated lines and arrows show 2 regions where mAChR5 and nAChR did not overlap). C, False color confocal $z$-stack of 5 images of quadruple immunohistochemical labeling of another P7 poly-innervated NMJ showing the diffuse distribution of mAChR5 (green), postsynaptic nAChRs ( $\alpha$-bungarotoxin; red), presynaptic terminals (NF-SV2; gray), and PSCs (S100 $\beta$; cyan). D, False color confocal $z$-stack of 5 images of quadruple immunohistochemical labeling of another P7 poly-innervated NMJ showing the distribution mAChR3. As for mAChR5, mAChR3 labeling was diffuse and uniform throughout the endplate area (red). Scale bars, $5 \mu \mathrm{m}$.

the state of innervation and territorial organization. As shown in Figure 9, we also observed both uneven (Figure 9C) and more uniform (Figure 9D) distributions of $\mathrm{P} 2{ }_{\mathrm{Y}} \mathrm{R}$ hotspots on monoinnervated NMJs. This indicates that the state of innervation and the presence of the overall synaptic strength of each nerve terminal did not account for the distribution of $\mathrm{P} 2{ }_{\mathrm{Y}} \mathrm{Rs}$.

\section{Discussion}

Here we show that glial cells at immature NMJs undergo similar interactions with their neuronal counterparts, as was shown for mature synapses. However, we reveal an additional level of sophistication whereby a single PSC interacts with two independent competing inputs at the same NMJ by decoding their synaptic efficacy based on selective activation of different receptor pools, level of transmitter release, and intrinsic properties of PSCs. These properties should allow PSCs to intervene actively in activity-dependent modulation of synaptic competition.

\section{Responsiveness of PSCs}

For PSCs to influence synaptic competition in an activitydependent manner, an important requirement was that they detect synaptic activity of competing nerve terminals. Similar to adult NMJs (Rochon et al., 2001; Todd et al., 2010), we showed that PSCs were as efficient in detecting transmitter release at this age and developmental stage as indicated by a reliable activation of PSCs (high percentage of responsive cells) that elicited robust and consistent $\mathrm{Ca}^{2+}$ elevation. 
Anti-P2Y1R
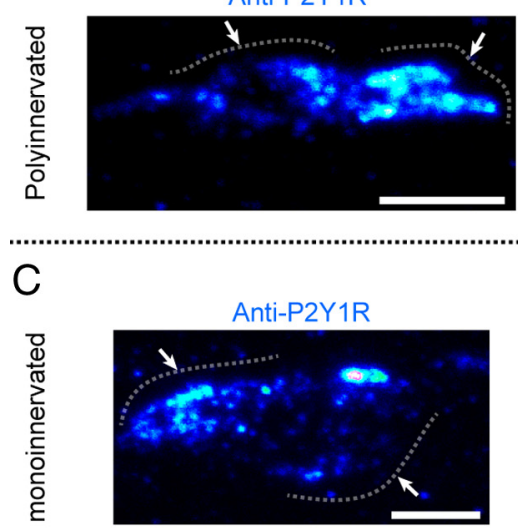

$\alpha$-Bungarotoxin

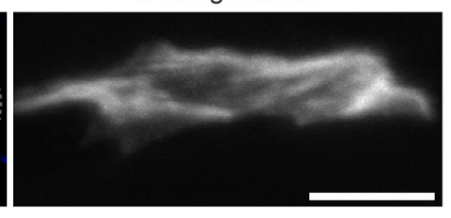

B Uniform distribution of P2Y1R

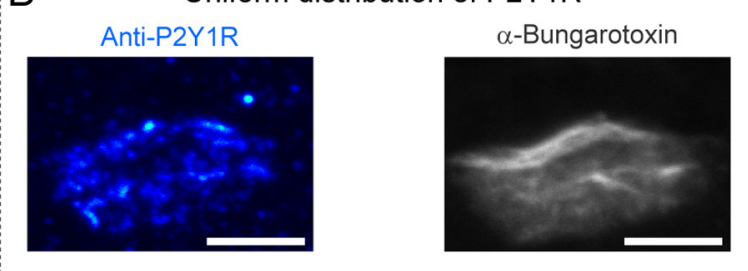

$\mathrm{D}$

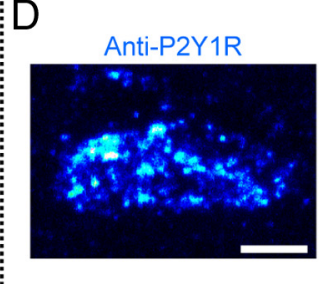

$\alpha$-Bungarotoxin

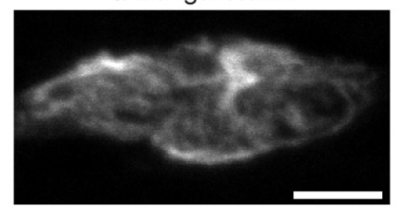

Figure 9. Territorial distribution of $\mathrm{P} 2_{\gamma} 1 \mathrm{R}$ receptors at poly-innervated and mono-innervated NMJs. $A$, False color confocal $z$-stack of 16 images of $P 2_{\gamma} 1 \mathrm{R}$ labeling (left; blue) showing two regions (dotted lines and arrows) of different fluorescence intensity at the NMJ. Black/dark blue represents low pixel intensity; and light blue/white, higher intensities. The corresponding AChR labeling delineates the endplate area (right; $\alpha$-bungarotoxin in gray). Note that the region on the right shows higher fluorescence intensity than the left one, suggesting that more $P 2_{\gamma} 1 R s$ were present. $B$, $z$-stack of 10 images of another poly-innervated NMJ showing a more uniform distribution of $P 2_{\gamma} 1$ Rs (left, blue) throughout the endplate area (right, $\alpha$-bungarotoxin in gray). $C$, $z$-stack of 8 images of a P7 mono-innervated NMJ showing a nonuniform distribution of P2Y1Rs where the left region had higher fluorescence intensity than the right one, suggesting that more $P 2_{\gamma} 1$ Rs were present (dotted lines and arrows) over the endplate area (right; $\alpha$-bungarotoxin in gray). D, z-stack of 10 images of another P7 mono-innervated NMJ showing a more uniform distribution of $P 2_{\gamma} 1$ Rs (left; blue) throughout the NMJ (right; $\alpha$-bungarotoxin in gray). Scale bars, $5 \mu \mathrm{m}$.

Interestingly, PSCs at mature and developing NMJs differ by the type of activated receptors. Indeed, PSCs at mature NMJs detect neurotransmitters using a combination of purinergic and muscarinic receptors (Rochon et al., 2001), whereas PSC activation solely depends on $\mathrm{P} 2{ }_{\mathrm{Y}}$ receptors during synaptic competition at the age studied. Hence, it appears that the purinergic receptor system is predominant during early developmental stages, even though the muscarinic receptor system was present and functional. The lack of muscarinic contribution to synaptic-induced PSC activation, even though the receptors are functional, may be the result of the absence of structured distribution of muscarinic receptors at proximity of active zones.

Therefore, a switch from a purinergic to a mixed muscarinic/ purinergic signaling during synapse maturation surely underlies a change in the properties and functions of the PSCs themselves. This is supported by changes in PSC properties after denervation and the expression of glial fibrillary acidic protein known to be regulated by muscarinic receptors (Georgiou et al., 1999). An interesting possibility is that different receptors play different roles so that the muscarinic regulation would mainly stabilize PSCs while the purinergic system would be less restrictive, thus more prominent during synapse formation and maturation where large functional and morphological changes occur. This is also supported by a study showing that PSCs at immature NMJs are highly dynamic, becoming more quiescent with age (Brill et al., 2011).

\section{One PSC, two synaptic inputs}

One of the challenges during synaptic competition and elimination is that a single PSC must integrate synaptic information from both competing inputs. A main constraint for a single PSC in such context is to elaborate a strategy to detect synaptic activity from both nerve terminals while maintaining its ability to segregate and identify each activation to a given nerve terminal.

As a whole, our data strongly argue that the selective detection of competing nerve terminals is achieved by maintaining a functional segregation of receptors, with $\mathrm{P} 2{ }_{\mathrm{Y}} \mathrm{R}$ clustered in hotspots at proximity of active zones. However, there was no clear territorial distribution of these receptors on a portion of a PSC, associated with a given nerve terminal, that could have explained their differential responsiveness to each input. Instead, our data suggest that this segregation is based on functional properties rather than on a nonuniform distribution of the receptors. Interestingly, the functional segregation of P2YRs and their preferential clustering at proximity of active zones are in accordance with the general organization of NMJs in the midsts of synaptic competition because each presynaptic terminal uses exclusive sets of postsynaptic receptors (Gan and Lichtman, 1998; Keller-Peck et al., 2001; Walsh and Lichtman, 2003; Wyatt and Balice-Gordon, 2003; Bishop et al., 2004). Knowing that the occupancy of the synaptic territory is quite dynamic and changes during the course of the competition (Turney and Lichtman, 2012), it would be of interest to determine whether PSC receptor properties and distribution also follow similar dynamic alteration in the course of the process.

Receptor distribution and density could also be a determining factor establishing PSC intrinsic properties. Indeed, the inability of TEA to further increase the size of $\mathrm{Ca}^{2+}$ responses elicited by synaptic activity could be explained by the presence of different number of receptors and/or receptors at some distance from the release sites. In these conditions, releasing more neurotransmitter would have little effect on PSC $\mathrm{Ca}^{2+}$ response because all receptors would be already optimally activated or that there would be sufficient time for the ecto-enzymes to degrade ATP before it reaches the PSC receptors (Robitaille, 1995). Furthermore, PSC receptor distribution and segregation may be regulated by the level of synaptic activity where PSCs could organize the distribution of its fine processes and receptors to optimize the detection of transmitter release occurring at single active zones. The distribution of purinergic receptors, but not the muscarinic ones, in the vicinity of active zones (identified by the SV2 labeling) strongly argues in favor of this interpretation.

In this study, specific $\mathrm{Ca}^{2+}$ responses to weak and strong terminals occur throughout the PSC soma. This has two main implications for the decoding of the two inputs. First, the different size of the $\mathrm{Ca}^{2+}$ transients does not carry the same information, 
possibly by activating different $\mathrm{Ca}^{2+}$-dependent mechanisms with different affinity for $\mathrm{Ca}^{2+}$. Second, because of the lack of evidence of morphological segregated distribution of receptors, we propose that the segregated functional distribution of receptors is complemented by the segregation of downstream intracellular machinery. Mechanisms, such as differential cellular machinery distribution or different calcium sources targeted to each nerve terminal, could be present. Such important intrinsic characteristics of PSCs properties will need to be further explored.

Finally, the differential coverage of competing terminals by PSCs could have been another mechanism explaining their differential activation. However, our data are not consistent with this observation. Indeed, according to this scenario at dually innervated NMJs where two PSCs are present, one could predict that each PSC would cover preferentially a synaptic territory associated with a given nerve terminal whereas the other one would preferentially interact with the other. Hence, if the differential coverage dictates the sensitivity of PSCs, a given PSC would systematically respond with a large $\mathrm{Ca}^{2+}$ response from the activity of a given terminal and smaller ones by the activity of the other. This situation would be reversed for the other PSC. However, as shown in Figure $3 F$, we never observed such a phenomenon, suggesting that the level of PSC coverage is not a determinant parameter and that $\mathrm{Ca}^{2+}$ responses of both PSCs reflected the state of synaptic competition. This is also in accordance with recent evidence showing that PSCs highly intermingle and overlap during early postdevelopmental stages while they occupy segregated, well-delineated territories in adulthood (Brill et al., 2011).

\section{Impact of PSCs decoding in synaptic competition and elimination}

The possible involvement of PSCs in the regulation of synaptic competition has been questioned in previous works where it was proposed that they served more a role of support for axon retraction (Hirata et al., 1997). However, their ability to dynamically decode synaptic strength using their $\mathrm{Ca}^{2+}$-dependent excitability provides strong evidence that PSCs are poised to play a critical role in influencing synaptic competition.

The PSC decoding ability could have different consequences for the regulation of synaptic competition and elimination. First, because of their ability to decipher between strong and weak inputs, as indicated by the different $\mathrm{Ca}^{2+}$ responses, it is possible that, in turn, PSCs differentially modulate synaptic efficacy of the competing terminals. For instance, consistent with their ability to decipher levels of synaptic activity at mature NMJs (Rousse et al., 2010; Todd et al., 2010), PSCs could further potentiate synaptic activity of the strong input, at the expense of the weakest one. Such modulation would bias the competition toward the strong input and, ultimately, the outcome of synaptic competition and elimination.

A second consequence could be related to the elimination of the redundant inputs. PSCs are known to actively clear cellular debris at developing NMJs, a critical feature of the developing nervous system (Song et al., 2008). Perhaps their ability to sort out the weak from the strong input would allow them to selectively target this metabolism to the weak terminal, thus participating actively in the shedding of axon terminals (Chung and Barres, 2009). This could be a central feature of synapse elimination because the mechanism of selecting the branches destined for elimination remains unknown (Song et al., 2008).

\section{Glial cells on synaptic elimination in the CNS}

The involvement of glial cells in the refinement of synaptic connectivity has also been addressed in the CNS. For instance, immature astrocytes participate in the axon pruning of redundant inputs by initiating the activation of the complement cascade (Cullheim and Thams, 2007; Stevens et al., 2007; Alexander et al., 2008). Also, genetic manipulation of $\mathrm{Ca}^{2+}$-permeable channels in Bergmann glia caused the retraction of glial processes ensheathing synapses, increased multiple innervations of Purkinje cells by climbing fibers and delayed synapse elimination (Iino et al., 2001). Hence, it is appealing to propose that astrocytes pruning of synapses could be related to their ability to interact with competing inputs and decoding their activity similarly to PSCs at the NMJ.

In conclusion, we report that PSCs decode ongoing synaptic competition and the state of competency and strength of each competing inputs. Because of their ability to modulate and control synaptic activity, their ability to decipher the state of synaptic competition would endow PSCs with a powerful mechanism to alter the outcome of synaptic competition, hence, the quality and reliability of synaptic wiring.

\section{References}

Alexander JJ, Anderson AJ, Barnum SR, Stevens B, Tenner AJ (2008) The complement cascade: Yin-Yang in neuroinflammation-neuro-protection and -degeneration. J Neurochem 107:1169-1187. CrossRef Medline

Auld DS, Robitaille R (2003) Glial cells and neurotransmission: an inclusive view of synaptic function. Neuron 40:389-400. CrossRef Medline

Balice-Gordon RJ, Lichtman JW (1994) Long-term synapse loss induced by focal blockade of postsynaptic receptors. Nature 372:519-524. CrossRef Medline

Bishop DL, Misgeld T, Walsh MK, Gan WB, Lichtman JW (2004) Axon branch removal at developing synapses by axosome shedding. Neuron 44:651-661. CrossRef Medline

Brill MS, Lichtman JW, Thompson W, Zuo Y, Misgeld T (2011) Spatial constraints dictate glial territories at murine neuromuscular junctions. J Cell Biol 195:293-305. CrossRef Medline

Buffelli M, Busetto G, Cangiano L, Cangiano A (2002) Perinatal switch from synchronous to asynchronous activity of motoneurons: link with synapse elimination. Proc Natl Acad Sci U S A 99:13200-13205. CrossRef Medline

Buffelli M, Burgess RW, Feng G, Lobe CG, Lichtman JW, Sanes JR (2003) Genetic evidence that relative synaptic efficacy biases the outcome of synaptic competition. Nature 424:430-434. CrossRef Medline

Busetto G, Buffelli M, Tognana E, Bellico F, Cangiano A (2000) Hebbian mechanisms revealed by electrical stimulation at developing rat neuromuscular junctions. J Neurosci 20:685-695. Medline

Chen C, Regehr WG (2000) Developmental remodeling of the retinogeniculate synapse. Neuron 28:955-966. CrossRef Medline

Christopherson KS, Ullian EM, Stokes CC, Mullowney CE, Hell JW, Agah A, Lawler J, Mosher DF, Bornstein P, Barres BA (2005) Thrombospondins are astrocyte-secreted proteins that promote CNS synaptogenesis. Cell 120:421-433. CrossRef Medline

Chung WS, Barres BA (2009) Selective remodeling: refining neural connectivity at the neuromuscular junction. PLoS Biol 7:e1000185. CrossRef Medline

Claes P, Van Kolen K, Roymans D, Blero D, Vissenberg K, Erneux C, Verbelen JP, Esmans EL, Slegers H (2004) Reactive blue 2 inhibition of cyclic AMP-dependent differentiation of rat C6 glioma cells by purinergic receptor-independent inactivation of phosphatidylinositol 3-kinase. Biochem Pharmacol 67:1489-1498. CrossRef Medline

Colman H, Nabekura J, Lichtman JW (1997) Alterations in synaptic strength preceding axon withdrawal. Science 275:356-361. CrossRef Medline

Cullheim S, Thams S (2007) The microglial networks of the brain and their role in neuronal network plasticity after lesion. Brain Res Rev 55:89-96. CrossRef Medline

Del Castillo J, Katz B (1954) Quantal components of the end-plate potential. J Physiol 124:560-573. Medline 
De Lorenzo S, Veggetti M, Muchnik S, Losavio A (2006) Presynaptic inhibition of spontaneous acetylcholine release mediated by $\mathrm{P} 2 \mathrm{Y}$ receptors at the mouse neuromuscular junction. Neuroscience 142:71-85. CrossRef Medline

Eken T, Elder GC, Lømo T (2008) Development of tonic firing behavior in rat soleus muscle. J Neurophysiol 99:1899-1905. CrossRef Medline

Eroglu C, Barres BA (2010) Regulation of synaptic connectivity by glia. Nature 468:223-231. CrossRef Medline

Fellin T, Pascual O, Gobbo S, Pozzan T, Haydon PG, Carmignoto G (2004) Neuronal synchrony mediated by astrocytic glutamate through activation of extrasynaptic NMDA receptors. Neuron 43:729-743. CrossRef Medline

Gan WB, Lichtman JW (1998) Synaptic segregation at the developing neuromuscular junction. Science 282:1508-1511. CrossRef Medline

Garcia N, Santafé MM, Salon I, Lanuza MA, Tomàs J (2005) Expression of muscarinic acetylcholine receptors (M1-, M2-, M3- and M4-type) in the neuromuscular junction of the newborn and adult rat. Histol Histopathol 20:733-743. Medline

Georgiou J, Robitaille R, Charlton MP (1999) Muscarinic control of cytoskeleton in perisynaptic glia. J Neurosci 19:3836-3846. Medline

Gorassini M, Eken T, Bennett DJ, Kiehn O, Hultborn H (2000) Activity of hindlimb motor units during locomotion in the conscious rat. J Neurophysiol 83:2002-2011. Medline

Henneberger C, Papouin T, Oliet SH, Rusakov DA (2010) Long-term potentiation depends on release of D-serine from astrocytes. Nature 463: 232-236. CrossRef Medline

Hirata K, Zhou C, Nakamura K, Kawabuchi M (1997) Postnatal development of Schwann cells at neuromuscular junctions, with special reference to synapse elimination. J Neurocytol 26:799-809. CrossRef Medline

Iino M, Goto K, Kakegawa W, Okado H, Sudo M, Ishiuchi S, Miwa A, Takayasu Y, Saito I, Tsuzuki K, Ozawa S (2001) Glia-synapse interaction through $\mathrm{Ca}^{2+}$-permeable AMPA receptors in Bergmann glia. Science 292:926-929. CrossRef Medline

Jahromi BS, Robitaille R, Charlton MP (1992) Transmitter release increases intracellular calcium in perisynaptic Schwann cells in situ. Neuron 8:1069-1077. CrossRef Medline

Keller-Peck CR, Walsh MK, Gan WB, Feng G, Sanes JR, Lichtman JW (2001) Asynchronous synapse elimination in neonatal motor units: studies using GFP transgenic mice. Neuron 31:381-394. CrossRef Medline

Kopp DM, Perkel DJ, Balice-Gordon RJ (2000) Disparity in neurotransmitter release probability among competing inputs during neuromuscular synapse elimination. J Neurosci 20:8771-8779. Medline

Lohof AM, Delhaye-Bouchaud N, Mariani J (1996) Synapse elimination in the central nervous system: functional significance and cellular mechanisms. Rev Neurosci 7:85-101. Medline

Nevian T, Helmchen F (2007) Calcium indicator loading of neurons using single-cell electroporation. Pflugers Arch 454:675-688. CrossRef Medline

Panatier A, Theodosis DT, Mothet JP, Touquet B, Pollegioni L, Poulain DA, Oliet SH (2006) Glia-derived D-serine controls NMDA receptor activity and synaptic memory. Cell 125:775-784. CrossRef Medline
Panatier A, Vallée J, Haber M, Murai KK, Lacaille JC, Robitaille R (2011) Astrocytes are endogenous regulators of basal transmission at central synapses. Cell 146:785-798. CrossRef Medline

Redfern P, Thesleff S (1971) Action potential generation in denervated rat skeletal muscle. I. Quantitative aspects. Acta Physiol Scand 81:557-564. CrossRef Medline

Robitaille R (1995) Purinergic receptors and their activation by endogenous purines at perisynaptic glial cells of the frog neuromuscular junction. J Neurosci 15:7121-7131. Medline

Robitaille R (1998) Modulation of synaptic efficacy and synaptic depression by glial cells at the frog neuromuscular junction. Neuron 21:847-855. CrossRef Medline

Rochon D, Rousse I, Robitaille R (2001) Synapse-glia interactions at the mammalian neuromuscular junction. J Neurosci 21:3819-3829. Medline

Rousse I, St-Amour A, Darabid H, Robitaille R (2010) Synapse-glia interactions are governed by synaptic and intrinsic glial properties. Neuroscience 167:621-632. CrossRef Medline

Song JW, Misgeld T, Kang H, Knecht S, Lu J, Cao Y, Cotman SL, Bishop DL, Lichtman JW (2008) Lysosomal activity associated with developmental axon pruning. J Neurosci 28:8993-9001. CrossRef Medline

Stellwagen D, Shatz CJ (2002) An instructive role for retinal waves in the development of retinogeniculate connectivity. Neuron 33:357-367. CrossRef Medline

Stevens B, Allen NJ, Vazquez LE, Howell GR, Christopherson KS, Nouri N, Micheva KD, Mehalow AK, Huberman AD, Stafford B, Sher A, Litke AM, Lambris JD, Smith SJ, John SW, Barres BA (2007) The classical complement cascade mediates CNS synapse elimination. Cell 131:1164-1178. CrossRef Medline

Todd KJ, Darabid H, Robitaille R (2010) Perisynaptic glia discriminate patterns of motor nerve activity and influence plasticity at the neuromuscular junction. J Neurosci 30:11870-11882. CrossRef Medline

Todd KJ, Robitaille R (2006) Purinergic modulation of synaptic signalling at the neuromuscular junction. Pflugers Arch 452:608-614. CrossRef Medline

Turney SG, Lichtman JW (2012) Reversing the outcome of synapse elimination at developing neuromuscular junctions in vivo: evidence for synaptic competition and its mechanism. PLoS Biol 10:e1001352. CrossRef Medline

Ullian EM, Christopherson KS, Barres BA (2004) Role for glia in synaptogenesis. Glia 47:209-216. CrossRef Medline

Walsh MK, Lichtman JW (2003) In vivo time-lapse imaging of synaptic takeover associated with naturally occurring synapse elimination. Neuron 37:67-73. CrossRef Medline

Wang X, Lou N, Xu Q, Tian GF, Peng WG, Han X, Kang J, Takano T, Nedergaard M (2006) Astrocytic $\mathrm{Ca}^{2+}$ signaling evoked by sensory stimulation in vivo. Nat Neurosci 9:816-823. CrossRef Medline

Wyatt RM, Balice-Gordon RJ (2003) Activity-dependent elimination of neuromuscular synapses. J Neurocytol 32:777-794. CrossRef Medline 